\title{
Geotechnical characterization of fine-grained spoil material from surface coal mines
}

\author{
Ioannis E. Zevgolis ${ }^{a}$, Alexandros I. Theocharis ${ }^{b}$, Alexandros V. Deliveris ${ }^{c}$, Nikolaos C. \\ Koukouzas ${ }^{d}$, Christos Roumpos ${ }^{e}$, Alec M. Marshall ${ }^{f}$
}

\author{
a School of Mining and Metallurgical Engineering, National Technical University of Athens, Greece

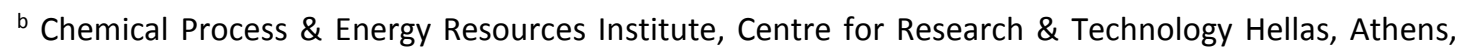 \\ Greece \\ ${ }^{\mathrm{c}}$ Chemical Process \& Energy Resources Institute, Centre for Research \& Technology Hellas, Athens, \\ Greece \\ ${ }^{d}$ Chemical Process \& Energy Resources Institute, Centre for Research \& Technology Hellas, Athens, \\ Greece \\ ${ }^{\mathrm{e}}$ Mine Planning Section, Public Power Corporation, Athens, Greece \\ f Nottingham Centre for Geomechanics, University of Nottingham, University Park NG7 2RD \\ Nottinghamshire, United Kingdom \\ *Corresponding Author: loannis E. Zevgolis, izevgolis@metal.ntua.gr
}

\begin{abstract}
:
Coal mines produce large amounts of excavated waste soils, known as spoils. These materials can cover vast areas, are typically dumped in heaps without any treatment and are difficult to exploit for engineering purposes because of their significant variability. Efficient exploitation of spoil heaps poses engineering challenges, related mainly to the involved degree of uncertainty. A small number of studies have attempted to characterize the geotechnical properties of spoil material; however, there remains a considerable gap in understanding how to deal with spoil materials in the context of sustainable development and civil infrastructure design. In this work, a systematic effort is made to quantify the uncertainty of the geotechnical properties of a particular spoil heap. Laboratory test results based on an extended investigation of a spoil material originating from lignite coal mines are gathered in one database and thoroughly analyzed. The results reveal and quantify the significant spoil material variability, which is contrasted against data for common soils, while a systematic approach is proposed for spoil material characterization.
\end{abstract}

Keywords: soil characterization, geotechnical uncertainty, spoil heap, waste dump, surface lignite mine, sustainability 
1

2

3

4

\section{Introduction}

For centuries, coal mining has been a large and essential industry based on extracting non-renewable coal resources from the ground. During this extraction process, vast amounts of overburden materials - approximately 1.45 billion tons per year (Bian et al. 2012) - are excavated to gain access to the coal deposits. These materials have been characterized as waste and dumped to massive spoil heaps (also known as spoil dumps or waste embankments), often without any treatment or consideration for future use. Sustainable management of wastes is a global priority, and considerable efforts target on properly exploiting them.

Spoil heaps consist of various soils, mixed randomly due to the excavation, transport, and deposition methods used within mines. The result is a material with a remarkably high degree of variability, creating a challenging construction scenario. Until recently, exploitation of spoil heaps has largely been limited to agriculture, forestry, and public leisure amenities (Bell and Donnelly 2006). Nonetheless, more efficient reclamation options for spoil heaps exist, such as renewable energy projects (Alves Dias et al. 2018), i.e., installing wind turbines, photovoltaic cells and ground source heat pumps. These systems involve high loads and complex load paths, posing engineering challenges intensified by the nature of spoil material. Consequently, a more rigorous characterization of spoil materials is needed. They are significantly heterogeneous, not subjected to standard soil norms, and typical geotechnical evaluations should be applied with caution.

Masoudian et al. (2019) presented an overview of several European lignite mine spoil heaps' geotechnical properties and concluded that they indicate a remarkable variability (more considerable than typical in situ soils). It is noteworthy that the heterogeneity of spoil materials is not only affected by natural processes, but also by the spoil's transportation method (belt conveyor vs haul trucks); the dumping method (spreaders vs trucks, and top-down with an angle of repose vs bottom-up in layers); the different origin of the soils (e.g. if they come from one or more mines with the same or different geology); and the duration and time planning of different construction stages (based on different mine development phases). The difficulties in quantifying the properties of spoil materials are reflected in several slope failure incidents that often lead to environmental hazards and cause social concern (e.g. 
Ulusay et al. 1996; Dawson et al. 1998; Steiakakis et al. 2009; Poulsen et al. 2014). Although several studies exist relating to spoil heaps' slope stability, very few include detailed geotechnical characterization of the spoil material (Okagbue 1984; Ulusay et al. 1995; Skarzyńska and Michalski 1998; Cadierno et al. 2014; Fityus et al. 2014; Li et al. 2016; Masoudian et al. 2019). A more in-depth analysis will lead to better insights, improved analysis, and safer, cost-effective, and sustainable design.

The present work focuses on the geotechnical characterization of a massive spoil heap in Greece, measuring $5 \mathrm{~km}$ in length and more than $150 \mathrm{~m}$ in height. This spoil heap is composed of overburden material from two surface lignite (brown coal) mines. According to development plans, an old national road and a railway line should soon be relocated on the spoil heap. Nonetheless, engineering challenges are yet to be solved as the spoil material (composed primarily of high plasticity silts) presents difficulties for analysis and design. Although no stability problems have been reported, efforts to predict the magnitude and completion time of ongoing consolidation settlements have failed.

An extensive database has been established in this work based on extended geotechnical investigations, and statistical analysis is employed for evaluating the results. Furthermore, crosscorrelations and dependencies between the spoil's geotechnical parameters are quantified to provide an in-depth understanding and input for reliability analysis. Moreover, available data are plotted and compared against well-known correlations from the literature, contrasting results for the spoil material against typical natural soils. Finally, the evolution of the spoil material with time (i.e. the effect of time on its engineering response) is tentatively evaluated for a six-year time interval. The present work adds to the relatively limited knowledgebase on spoil heaps contributing to the fields of circular economy and sustainable geotechnics.

\section{The Soulou spoil heap - background information}

Greece is one of the leading lignite producers in Europe, with 37.7 million tons of lignite mined in 2017 (Euracoal 2018). Several large lignite mines (often lying at $150-200 \mathrm{~m}$ depth, with an inclination of $10^{\circ}$ $15^{\circ}$ ) have been developed in northwest Greece. During the last 15 years, the stripping ratio (the volume of waste material to produce 1 ton of lignite) has been about $4-5 \mathrm{~m}^{3} /$ ton (Roumpos et al. 2018). Hence the management of these large volumes poses a constant challenge from a geotechnical perspective. 
This study relates to the massive Soulou spoil heap, created from lignite mines' excavations in Ptolemais (northwest Greece). The heap was constructed on a depleted mining area, between two principal lignite surface mines (Kardia and South Field). Figure S1, found in the supplemental material, presents a general view of the area including part of the spoil heap and the nearby power plants; Figure S2 (in the supplemental material) presents a simplified plan view of the heap, including the location of boreholes. Ground profiles in mines' excavations consist of a thick overburden zone of sterile materials (Quaternary deposits of several tens of meters) that overlay the exploitable lignite deposits (Neogene deposits). The lignite deposits often alternate with thin intermediate layers of sterile material. The sterile material mostly consists of marls and clays - often stiff to hard - and occasionally of weak conglomerates and water-bearing sands.

The construction of the spoil heap started in 1999. Figure S3 shows a representative cross-section ( $A^{\prime}$ $\left.A^{\prime \prime}\right)$ on the spoil heap's longitudinal axis, along with an indication of the construction periods. The heap's maximum height was reached in 2009; since then, only widening has taken place. The Soulou spoil heap is currently about $5 \mathrm{~km}$ in length, 0.4-2.1 km wide at its top, $1.8-3.65 \mathrm{~km}$ wide at its base, and 150-170 $\mathrm{m}$ in height. The importance of the Soulou spoil heap is related to its considerable size. According to the current plans, an old national road and a railway line will be relocated on the spoil heap. These relocations will contribute to the sustainable use of the area (given the practical usage of excavated materials as embankment material) and allow the adjacent lignite mines' uninterrupted operation.

Nonetheless, engineering challenges related to these plans are yet to be solved. In this context, in 2010, the mine owner (P.P.C.) conducted an extensive geotechnical investigation. Among others, the investigation included twelve sampling boreholes (B1 to B12), each being about 40-50 m deep, drilled along the embankment axis (Figure S2). Laboratory tests were conducted on several samples: index property tests (grain size with sieves, liquid and plastic limit tests), physical property measurements (water content, unit weight, specific gravity), and engineering property evaluation (unconfined compression test, consolidated - undrained triaxial compression tests with pore pressure measurements, and 1D consolidation tests). In the present work, the data obtained from these tests are systematically analyzed to assess the spoil heap's geotechnical characteristics and treated statistically to quantify the material's variability. 


\section{Characterization of the Soulou spoil heap}

\subsection{Overview}

A preliminary approach towards the characterization of the Soulou spoil material was made by Zevgolis et al. (2018b); a variety of additional information and a more rigorous analysis is herein presented. The classification of spoil materials according to the Unified Soil Classification System (USCS), over depth and along the longitudinal axis of the dump, is presented in Figure $\mathrm{S} 4$ (an updated version of Figure 11 in Zevgolis et al. (2018b), with the addition of two extra boreholes). A great variety of different soil types appear in a spatially random arrangement, ranging from (coarse-grained) gravels and sands to (fine-grained) silts and clays. Such classification provides the first approach in identifying different layers or even more a stratigraphy; however, no distinction of separate layers can be established. Furthermore, not even one particular structure can be easily identified, as different materials are intertwined, creating formations that cannot lead to organized patterns. Compared to more common geotechnical cases, this extreme complexity needs additional evaluation to organize the spoil materials. In a further attempt to distinguish possible soil layer trends or structures, effective friction angle $\phi^{\prime}$ and effective cohesion c' were considered (determined through undrained triaxial tests; more details are provided in the next section). Figure 1 presents the variation of these two mechanical parameters with depth; the data do not show any clear trend. Other geotechnical properties, such as uniaxial compression strength, constrained modulus and coefficient of permeability, were also assessed similarly; however, discernible patterns were not identified.

Besides, the construction methods of the spoil heap suggest a soil mix with a nearly chaotic nature. Waste ground materials were transported to the dump site primarily by continuous methods (conveyor belts with spreaders), and secondly by discontinuous means (haul trucks). These two methods result in differing states of the ground material at the location of deposition. Additionally, the dumping method was not always consistent; bottom-up and top-down dumping directions were employed at different times, while the original topography was initially flat or inclined. In general, bottom-up constructed dumps are expected to demonstrate better engineering properties than those made using top-down methods (Zevgolis 2018). Furthermore, the heap was created from waste material from two different 
mines, indicating a different origin of the spoil materials (given that even adjacent mines have experienced different geologic phenomena and tectonics). Finally, quite often, disposal of certain layers might have ceased for reasons related to the mine's production and then started again after some time (which might be months or even years). In this case, different parts of the dump have experienced different degrees of consolidation.

All these add to previous conclusions and further support that a general stratigraphy or characterization of layers with depth cannot be identified. Given the spoil material's disordered structure, it is reasonable to employ a statistical treatment of the heap as a single material with significant inherent variability, expressed in common statistical moments (mean values, standard deviations); this approach is used for the following analysis. Thus, the spoil heap's geotechnical characterization and the data's statistical process are implemented considering one soil layer.

An overview of the USCS classifications (Figure S4) indicates that the fine-grained materials define the spoil heap's overall response. Based on the samples examined in the laboratory, 92 out of 128 (72\%) were characterized as fine-grained material. In particular, 63 samples were characterized as silts (52 $\mathrm{MH}$ and $11 \mathrm{ML}), 11$ as clayey silts / silty clays (CL-ML), and 18 as clays (12 CL and $6 \mathrm{CH})$. There was always a significant percentage of fines for the rest of the samples, significantly influencing their engineering response. More specifically, 14 samples were classified as gravel with a fines percentage between $14 \%$ and $45 \%(G M, G C, G C-G M)$, and another 20 samples were classified as sands with more than $35 \%$ fines (SC, SM, SC-SM). Only two samples were characterized as SP-SM, with a percentage of fines approximately $10 \%$. Given a consensus that the fines would dominate the spoil's response, it was concluded that all samples should be employed within the statistical evaluation of the spoil heap since they all contained a substantial percentage of fines. A similar analysis excluding non-fine-grained samples (not presented herein) showed that results were practically the same (statistical parameters, cross-correlations etc.), further supporting the decision of including all samples in the evaluation.

Despite the spoil's significant variability, if defined as a single soil mass, the most appropriate classification would be a silty material (MH, ML). In particular, 74 out of the 128 samples tested, corresponding to $57 \%$, were classified as silt (predominantly $\mathrm{MH}$, and secondarily $\mathrm{ML}$ and $\mathrm{CL}-\mathrm{ML}$ ), with mean values of geotechnical parameters generally in agreement with silts (demonstrated later). 
The statistical analysis of the geotechnical properties that follows uses common statistical definitions.

The main parameters are the mean $(\mu)$ and median $(\tilde{\mu})$ values, the standard deviation $(\sigma)$ and the corresponding coefficient of variation (COV), while minimum-maximum values and ranges are also presented. Reported COV values for natural soils are presented for comparison in Table S1 of the supplemental data, as in Zevgolis et al. (2018b).

\section{$\underline{3.2 \text { Classification and Index properties }}$}

A critical population ( $n$ ) of samples was used; grain size characteristics, Atterberg limits, soil unit weights, specific gravities, and water contents of the spoil heap are summarized in Table 1. ASTM C136, ASTM D4318-83, ASTM D854-14 and, ASTM D 2216 standards were followed. Fine-grained materials dominate with an average frequency of $57 \%$ within the spoil heap body. Sandy materials occur with an average frequency of $32.5 \%$, and finally, the gravel fraction has an average of $10.5 \%$. Uncertainty in the determination of grain size distribution decreases with the increase of the frequency. Specifically, for the most frequently encountered fine fraction, the computed coefficient of variation (COV) is the lowest $(30 \%)$; for the less frequent gravel fraction, COV is the highest $(133 \%)$; for the sand fraction, COV is withinin this range, closer to the fine-grained (38\%).

Liquid Limit (LL) and Plasticity Index (PI) are jointly plotted for all samples (104 in total) in Figure S5. Largely silts of either (primarily) high ( $\mathrm{MH}$ ) or (secondarily) low (ML) plasticity are depicted. A significant amount of clay samples, primarily of low plasticity $(\mathrm{CL})$ rather than high plasticity $(\mathrm{CH})$, are also observed. Mean values of Liquid Limit (LL), plastic limit (PL) and Plasticity Index (PI) are 51, 34 and 16, respectively (Table 1), generally referring to high plasticity silt.

Moreover, Figure 2 presents the histograms of LL and PL. For each case, both normal and lognormal distributions were examined. These two distributions, which are arguably the most commonly employed, were selected because of their ability to fit many natural phenomena and because they can be easily adopted in engineering practice. Based on goodness-of-fit tests (details of the relevant tests fall beyond the present study's scope), the normal distribution was better in both cases. Additionally, the mean value and the distance of one standard deviation from the mean are included in Figure 2. The 
Liquid Limit (Figure 2(a)) presents a relatively normal distribution with a peak at 55\%-60\%; this can be additionally assessed in the plasticity chart of Figure S5.

Furthermore, the relative frequencies are larger for the high plasticity materials, further validating the assumption of a high plasticity silt as a characteristic and representative material of the whole spoil heap. The distribution could be roughly approximated with a normal distribution; however, a concentration of values larger than the mean indicate a slight shift of the distribution to the right. Furthermore, the plastic limit (Figure 2(b)) presents two peaks at $15 \%-25 \%$ and $35 \%-45 \%$; the normal distribution, in this case, cannot describe the first peak at $15 \%-25 \%$, but the majority of the measurements (62/103) still lie within one standard deviation. As a result of the LL (mean 51, varying between 20 and 85 ) and PL (mean 34, varying between 15 and 65) distributions, PI values for all samples gather within the range $5 \%-25 \%$.

For 63 out of 104 samples ( $61 \%$ of the sample population), LL was larger than 50 (i.e. samples of high plasticity). On the other hand, in terms of water content (w) with respect to Plastic and Liquid Limits, w lied between PL and LL in only 58 out of 104 samples, while $w>$ LL for 18 samples and $w<$ PL for 28 samples. In other words, a noteworthy part (about 17\%) can be considered as a very soft, normally consolidated material. In comparison, another significant part (27\%) can be considered as a material in a semi-solid state, most probably over-consolidated. The rest of the samples (56\%) lie somewhere in between the typical range of plastic solid state (i.e. $\mathrm{PL}<\mathrm{w}<\mathrm{LL}$ ). The corresponding COVs of $\mathrm{LL}, \mathrm{PL}$, and $\mathrm{PI}$ are $24 \%, 34 \%$ and $44 \%$. As expected, the latter is largest, given that it is a function of the other two. These values are towards the upper limits of the literature, where fine-grained materials may often have COVs of $30 \%$ or more for $\mathrm{LL}$ and PL, and up to $80 \%$ for PI (Baecher and Christian 2003).

Based on 132 samples, the average water content was computed to be almost $40 \%$ with a COV equal to $45 \%$. This COV is close to the upper limit of a wide range of literature COV values, ranging from negligible up to almost $65 \%$ for clays and silts (nonetheless, as stated by Baecher and Christian (2003), most sites demonstrate considerably smaller values than 65\%). In addition to LL, PL, and PI, the Liquidity Index (defined as $\mathrm{LI}=[\mathrm{W}-\mathrm{PL}] /[\mathrm{LL}-\mathrm{PL}]$ ) is also used. A mean value of $\mathrm{LI}$ equal to 0.27 characterizes a soil that on average behaves plastically, or in a moldable way $(0<\mathrm{LI}<1)$; additionally, this value describes a soil whose behavior tends towards a soft material, as it is closer to 0 than to 1 . In 58 samples, LI ranges 
between 0 and 1 (typical behavior), in 28 samples, LI was smaller than 0 (typical for over-consolidated material), and in 18 samples LI was larger than 1 (typical for normally consolidated material). In fact, in 10 samples, the LI was computed larger than 1.2, often reported for sensitive soils (Means and Parcher 1963). Finally, the large range and $\operatorname{COV}(253 \%)$ of $L I$ is due to the cumulative effect of $L L, P L$, and $w$.

In the following text and figures, "characteristic spoil samples" are employed to describe a material which would behave as a "reference", average material of the heap, around which the variability exists. The three characteristic samples were obtained from three depths: $2 \mathrm{~m}, 16 \mathrm{~m}$ and $30 \mathrm{~m}$. The grain size distribution curves from the characteristic spoil samples are presented in Figure $\mathrm{S} 6$ of the supplemental data. The three samples are classified as high plasticity silts with $\mathrm{PI} \approx 13 \%$ and $\mathrm{LL} \approx 57 \% ; 30 \%$ to $45 \%$ sand, a small portion $(<5 \%)$ of gravel, and the rest $(55 \%-70 \%)$ being fines (silts and clays). These samples can be taken as representative of the present spoil heap and are further analyzed in the following sections through oedometer and triaxial tests to describe a "reference behavior" for the spoil.

Basic statistics for physical parameters such as moist and dry unit weight and specific gravity are also provided in Table 1. The mean values of the moist and dry unit weight are relatively low $\left(16.9 \mathrm{kN} / \mathrm{m}^{3}\right.$ and $12.6 \mathrm{kN} / \mathrm{m}^{3}$, respectively), indicating the material's fine-grained and cohesive character. In general, unit weight and density demonstrate significantly less variability than most other soil parameters regardless of the type of soil (coarse- or fine-grained). Reported COVs are typically less than 10\% (Lumb 1974; Baecher and Christian 2003) as (a) unit weights of soils highly depend on the specific gravities of soil minerals, typically varying within a very narrow range, and (b) measuring unit weight is a reasonably precise procedure. In the present work, the scatter of unit weights is larger than usually reported, obtaining values of $13 \%$ and $24 \%$ for moist and dry unit weight, respectively. On the other hand, a typical level of scattering was computed for specific gravity (6\%); however, note that, in the present case, the mean specific gravity is 2.55 , which is lower than the usual range of 2.6-2.8 for inorganic soils.

From the grain size characteristics, index, and physical properties, it is concluded that their distributions and mean values support a single soil layer's choice for the spoil material. The spoil's chaotic nature and the absence of stratigraphy or basic structure are further validated. The COVs reported in this work are large and, though in some cases they lie within literature limits, they are near the upper end. Notice the literature's upper limits refer by definition to extreme cases, such as the one presented herein. 
Moreover, intermediate silt is the dominant spoil material, even though many soils are present. Thus, Soulou's spoil material lies within the intermediate soil fraction category of silts, implying a unique behavior, increasing the difficulty in predicting its behavior.

\subsection{Engineering Properties}

During the investigation, 43 consolidated undrained triaxial compression tests with pore pressure measurement (CU-PP) were conducted according to ASTM D2850-82. Table 2 provides statistical results concerning the Mohr-Coulomb parameters of effective friction angle $\left(\phi^{\prime}\right)$ and effective cohesion $\left(c^{\prime}\right)$. As far as the friction angle is concerned, the mean and the standard deviation are $25.2^{\circ}$ and $6.8^{\circ}$, respectively. In recent design frameworks, the mean value is not directly used for design; e.g. in Eurocode 7, the so-called characteristic value $X_{k}$ (and eventually the design value $X_{d}$ ) of a soil property is used. Schneider (1997) demonstrated that an approximation of $X_{k}$ is half a standard deviation below the mean $\left(X_{k}=\mu-0.5 \sigma\right)$, a definition that has gained wide acceptance (Orr and Farrell 2000). Thus, the characteristic value of the friction angle is $21.8^{\circ}$, considering the large, quantified variability.

Figure 3 shows the histograms of $\phi^{\prime}$ and $c_{c}$. The effective friction angle presents a distribution challenging to interpret with several gaps, especially at values lower than the mean (Figure 3(a)). Any type of typical distribution is not strictly appropriate for these data, and special treatment might be considered. As far as scattering is concerned, the COV of the friction angle was computed as $27 \%$, towards the upper literature limits for cohesive soils (corresponding to extreme cases).

Cohesion presents an extremely large COV (106\%) and a large difference between the mean (17.6 kPa) and the median $(11.7 \mathrm{kPa}$ ) value. More than a quarter of the cohesion measurements (12 out of 43 ) were found equal or almost equal to zero. From a design point of view, the characteristic value drops to $8.3 \mathrm{kPa}$ incorporating the large standard deviation. Effective friction angle ( $\phi$ ') and effective cohesion (c') are decisive for standard prediction methods of the behavior and failure of soils; however, in the case of spoil heaps, their use should be treated with caution because of the considerable uncertainty. Due to their demonstrated variability, it is unlikely that design parameters would provide consistently reliable results within typical deterministic analyses of spoil heaps. The nature of the material is such that probabilistic analysis might be the only possible way to obtain reliable results. 
The triaxial stress-strain data of the three characteristic samples are shown in Figure 4, for mean effective stress $p^{\prime}=200 \mathrm{kPa}$. A typical triaxial path is followed with constant cell pressure and increase of the vertical load with simultaneous measurement of the pore pressure. The three different depths are representative for the depth of the geotechnical investigation performed on the upper 50 meters. This behavior could be implemented as the characteristic constitutive behavior of the spoil material.

Moreover, 44 uniaxial compression tests were conducted according to ASTM D2166-66, and their compressive strength $q_{u}$ lies in Table 2 . The variability of $q_{u}$ was computed as $C O V=77 \%$, a value within the literature range, but again towards the upper limits. For instance, Baecher and Christian (2003) reported a COV range between 6 and 100\%, and they considered a reasonable value to be around $40 \%$. The mean value of $q_{u}$ is $104 \mathrm{kPa}$ and gives a corresponding undrained shear strength $\mathrm{s}_{u}=\mathrm{q}_{u} / 2=52 \mathrm{kPa}$ (however, this method of estimating su has been criticized by many researchers; hence its result should be used with caution). For this reason, further consideration, and elaboration on $q_{u} / s_{u}$ lab test results are avoided, and the undrained behavior of the spoil material is not further discussed.

Furthermore, 66 1D consolidation tests provided the compressibility of the spoil material, according to ASTM D2435-80. Table 2 summarizes the statistical parameters for the coefficient of permeability (k), the constrained modulus $\left(E_{s}\right)$, and the compression $\left(c_{c}\right)$ and recompression $\left(c_{r}\right)$ indices. Additional data for $k, E_{s}$ and $c_{v}$ at different stress levels than the reference tests are in Table S2. The mean value of $k$, for a reference stress increment of $100 \mathrm{kPa}$, is $4.9 \times 10^{-7} \mathrm{~cm} / \mathrm{s}$ and decreases slightly (but in the same order of magnitude) for higher vertical stress. In general, this k refers to soils of very low permeability, such as clays utilized to construct earth dam impermeable sections (e.g. Holtz et al. 2010); the COV of $\mathrm{k}$ was found to be close to $100 \%$. Surprisingly, this is not very large, considering that literature values range between $50 \%$ and $200 \%$ (Benson 1993), or even $200 \%$ and $300 \%$ (Lumb 1974). In any case, results indicate a rather impermeable silt-like material, per the results from previous sections.

Regarding the constrained modulus of elasticity $E_{s}$, an average value of $1.9 \mathrm{MPa}$ was computed for the reference stress range of $50 \mathrm{kPa}-100 \mathrm{kPa}$, inferring a very compressible and soft soil material. The COV associated to the above central value is $58 \%$, larger than typical COVs (usually around $30 \%$ to $40 \%$ ). For higher stress increments, $E_{s}$ increases (for instance, up to $6.4 \mathrm{MPa}$ for the step of 400 to $800 \mathrm{kPa}$ ) but is still low. The coefficient of consolidation $\left(c_{v}\right)$ results from both the permeability and the compressibility 
of the soil material. It has a mean value of $7.2 \times 10^{-3} \mathrm{~cm}^{2} / \mathrm{s}$ for the reference value of $100 \mathrm{kPa}$ and cannot be easily compared to the literature since typical values of $c_{v}$ are generally site- or region-specific. Regarding the uncertainty of $c_{v}$, the computed COV is equal to $79 \%$, a value towards the upper limits of the typical ranges (for instance, Baecher and Christian (2003) give a range of $25-100 \%$, with a suggested value of $50 \%)$. Concerning the minimum and maximum values $c_{v}$, these vary between two orders of magnitude, $10^{-2}$ to $10^{-4} \mathrm{~cm}^{2} / \mathrm{s}$, as expected based on the variation of $\mathrm{k}$.

Mean and median values of the compression index $c_{c}$ are 0.216 and 0.194 . These are typical values for uniform silts, according to USACE (1990), or a lower boundary value for normally consolidated medium sensitive clays (Holtz et al. 2010). The histogram for $c_{c}$ is provided in Figure 3(b), showing a relatively smooth distribution that can adequately be fitted with a lognormal distribution, implying higher frequencies in values lower than the mean. The mean and median recompression index $\mathrm{c}_{\mathrm{r}}$ both equal 0.037. This value is relatively large since, for instance, Leonards (1976) mentions typical $c_{r}$ range between 0.015 and 0.035 , where the lower values are for clays of low plasticity and low OCR.

On the other hand, the ratio $c_{r} / c_{c}$ is 0.17 , on the upper limit of the normal range. For example, Holtz et al. (2010) state that, in the absence of specific test data, this ratio may be assumed to be between 0.05 and 0.10, while Terzaghi et al. (1996) state that most values vary between 0.02 and 0.20 . In particular, Terzaghi et al. (1996) mention that values close to 0.20 correspond to micaceous silts and fissured stiff clays. The characteristic value of $c_{c}$ is 0.17 and of $c_{r} 0.029$. These values consider the standard deviation of the statistics and are closer to typical literature values. Use of these values for spoil material still requires caution due to their observed variability (though their variability is lower than for the shear strength parameters). The COVs for both compressibility indices are about $40 \%$, within the range of $20 \%$ and $50 \%$ indicated by Baecher and Christian (2003). The 1D consolidation test results of the three characteristic spoil samples are presented in Figure 5. The constrained modulus results are reasonably consistent for the three characteristic samples and indicate a very compressible material with low $E_{s}$ (e.g. $E_{s}=0.5 \mathrm{MPa}-1 \mathrm{MPa}$ for $\sigma^{\prime}{ }_{\mathrm{v}}=0.1 \mathrm{MPa}$ ). Furthermore, despite the differing initial void ratios (e) of the samples, the compression and recompression indices indicated in Figure 5(b) are remarkably similar.

From the 66 1D consolidation tests, the full consolidation curves were available only for the 44 of them. For these 44 tests, the pre-consolidation pressure $\left(p^{\prime}{ }_{c}\right)$, i.e. the maximum effective vertical overburden 
stress sustained in the past, was estimated based on Casagrande's graphical method (Holtz et al. 2010). Additionally, the vertical effective stress $\left(\sigma^{\prime}{ }_{v}\right)$ was calculated based on each soil element's depth and its measured dry unit weight. Based on these calculations, most of the samples (36 out of 44 , i.e. $82 \%$ ) show over-consolidation ratios $\left(\mathrm{OCR}=\mathrm{p}_{\mathrm{c}}{ }_{\mathrm{c}} / \sigma^{\prime} \mathrm{v}\right)$ lower than 1 , indicating that the spoil material is underconsolidated. Dry unit weight was used in the calculations, an assumption providing the lowest possible $\sigma^{\prime}{ }_{v}$ (and highest OCRs) regardless of the water table's actual position. From the under-consolidated samples, 24 provide OCRs between 0.2 and 0.5 , and 12 samples between 0.5 and 1 .

In contrast to this, sterile overburdens in Ptolemais mines (the material that eventually ended up in the spoil heap) are considered to have undergone gravitational consolidation with overburden pressures corresponding to 150-200 m of fill and being over-consolidated (Kavvadas et al. 2020). Nonetheless, detailed data are not available to allow a direct comparison. In any case, the OCRs imply excessive pore water pressures and ongoing consolidation due to self-weight loading during the continual deposition process. The human-made highly-disturbing process (excavation with heavy bucket-wheel excavators, transportation with continuous and discontinuous means, and continuous deposition and surcharge loading) has resulted in this type of behavior.

Overall, the Soulou's spoil material can be characterized by compressibility and consolidation behavior, as a plastic soil of high compressibility and low drainage capacity. Additionally, the variability of its parameters commonly lies near the upper limits of typical coefficients of variation (or even exceed them), leading to high uncertainty levels. Given its intermediate behavior and considering the high variability, analyses of the spoil heap's engineering performance using conventional methods could give misleading or erroneous results.

\section{Cross correlations among parameters}

An extensive cross-correlation analysis was performed among all the geotechnical properties of the Soulou spoil heap. Results were obtained in terms of coefficients of linear correlation $\rho$ (a normalized form of the covariance of two variables) among the parameters and are displayed in the form of a correlation matrix in Table 3. When two variables are perfectly correlated, $\rho$ is equal to \pm 1 (positively or negatively correlated). When two variables are entirely independent, $\rho$ is equal to 0 , while values 
between 0 and 1 (or 0 and -1 ) indicate intermediate correlations. As simple linear regression is only used in this study, the coefficient of determination (usually denoted $r^{2}$ or $R^{2}$ ) can also be obtained from the square of $\rho$. Details on the computation of the linear correlation coefficients and the coefficient of determination can be found within relevant textbooks (e.g. Harr 1987; Baecher and Christian 2003).

Based on the correlation matrix (Table 3), strong correlations exist among various physical properties. For instance, the Atterberg limits LL and PL are strongly correlated to each other $(\rho=0.82)$, and also to moist unit weight $\gamma(\rho=-0.72$ and -0.80 , respectively), to natural water content $w(\rho=0.80$ and 0.85 , respectively), and to initial void ratio $e_{o}(\rho=0.81$ and 0.87 , respectively). In other words, as $L L$ or $\mathrm{PL}$ increase, $w$ and $e_{o}$ increases, while $\gamma$ decreases. The unit weight $\gamma$ is strongly correlated negatively to $w$ and $e_{o}\left(\rho=-0.73\right.$ and -0.88 , respectively), while $w$ is strongly correlated positively to $e_{o}(\rho=0.93)$. All these tendencies are reasonable. On the other hand, there is no noteworthy linear dependency among physical and engineering parameters, except for some intermediate $\rho$ between Atterberg limits and compression/recompression indices. These are discussed in the following section. In any case, there are severe limitations to the use of these correlations, especially because coal spoil material is very variable and due caution should be exercised while using them.

In terms of correlation between engineering parameters, a strong negative correlation is observed between drained effective cohesion $c^{\prime}$ and effective friction angle $\phi^{\prime}$, presented in the scatter diagram of Figure $6(\mathrm{a})$. The linear correlation coefficient $\rho=-0.74$ also manifests this correlation. Many researchers have cited similar correlations: Lumb (1970) computed values between -0.37 and -0.70 , Wolff (1985) and Cherubini (2000) mentioned values of -0.47 and -0.61 , respectively, Yucemen et al. (1973) reported a range of -0.49 to -0.24 , Zevgolis et al. (2018a) cited a range of -0.86 to -0.1 . The spoil material gives a negative cross-correlation between $c^{\prime}$ and $\phi^{\prime}$ that lies in the lower limits of the literature range, suggesting a strongly negative correlation. On the other hand, the parameters of effective cohesion $c^{\prime}$ and effective friction angle $\phi^{\prime}$ do not significantly correlate with any other parameter, indicating the difficulty in reliably evaluating them through available empirical correlations with physical parameters. For instance, the coefficient of linear correlation between PI and $\phi^{\prime}$ (for which the literature provides some well-known empirical correlations) is -0.24 . Figure $6(\mathrm{~b})$ illustrates the covariance of the two parameters: there is, as expected, evidence that the increase of plasticity leads 
to a decrease in effective friction angle. Nonetheless, the well-known empirical curve from Terzaghi et al. (1996) may only serve as an upper boundary (non-conservative) rather than a mean estimate.

The common variation of $c_{c}$ and $c_{r}$ provides an intermediately positive correlation with $\rho=0.50$. Figure 7 illustrates the lower and upper limits of the ratio $c_{r} / c_{c}$ between 0.10 and 0.30 . At the same time, $c_{c}$ appears intermediately correlated with easily derived physical parameters, such as LL ( $\rho=0.41$, Fig. 8(a)), PL $(\rho=0.50), w(\rho=0.45)$, and $e_{o}(\rho=0.46)$. The widespread empirical correlation $c_{c}=0.009(L L-$ 10) for undisturbed clays (Terzaghi and Peck 1967) may only work as an upper limit for the examined data. Similarly, the empirical correlation $c_{c}=0.007(L L-10)$ for disturbed clays (Skempton and Jones 1944), provides only a general overestimation of $c_{c}$ (Figure 8(a)). Concerning the relationship between $c_{c}$ and $w$ and $c_{c}$ and $e_{0}$ (Figure S7), well-known empirical correlations may only serve as upper limits to the data.

In summary, classic empirical correlations tend to overestimate $c_{c}$, suggesting that the spoil material is more compressible than expected, as previously inferred. As a result, well-known relations should be applied with caution, keeping in mind that they tend to overestimate $c_{c}$ and could overestimate settlements. Finally, $\mathrm{c}_{\mathrm{c}}$ demonstrates an intermediate dependency on the coefficient of permeability $\mathrm{k}$ $(\rho=0.52)$, and a strong dependency on the constrained modulus $E_{s}$ (expected, given that both $c_{c}$ and $E_{s}$ are derived from the same 1D oedometer curves).

The recompression index $c_{r}$ presents intermediate correlations with Liquid Limit (LL) and the Liquidity Index (LI) with $\rho=0.52$ and $\rho=0.49$, respectively. Figure $8(\mathrm{~b})$ present $\mathrm{Cr}_{r}$ and $\mathrm{LL}$, along with the empirical equation $C_{r}=0.0007(L L+8.857)$ suggested by Işık (2009). It seems that this equation created for all types of clays fits the present data reasonably well. Both $\mathrm{c}_{\mathrm{c}}$ and $\mathrm{LI}$, and $\mathrm{c}_{\mathrm{r}}$ and $\mathrm{LI}$ (Figure S8), present an overall linear trend but with a large scatter. It is concluded that (in contrast to $\phi^{\prime}$ and $c^{\prime}$ ) an informed assessment of $c_{c}$ and $c_{r}$ could be attempted using only physical parameters. Finally, a very strong negative cross-correlation is noted between initial void ratio e e and moist unit weight $\gamma$, corresponding to a linear correlation coefficient of $\rho=-0.88$ (Figure S9). 


\section{Evolution over time}

The geotechnical investigation program performed in 2010 was followed by a second program in 2016 that consisted of six additional sampling boreholes drilled $40 \mathrm{~m}$ deep. The new boreholes along spoil dump's central axis generally lied in between the 2010 boreholes, with the new boreholes' head at approximately the same elevation as the previous ones. Despite the continual deposition of excavated spoil from the two nearby mines between 2010 and 2016 (see Figure S3), the dump's height around the central axis was practically constant. Thus, due to only slight differences in the old and new boreholes' elevation, data from the two investigations are treated in a unified manner. In this way, the impact of time on the geotechnical properties of spoil can be investigated.

The data derived from the 2016 geotechnical investigation program consists of 48 Atterberg limits tests, three consolidated undrained triaxial tests with pore pressure measurements, 26 uniaxial compressive strength tests, and 15 1D consolidation tests. The effective friction angle and the effective cohesion did not present any measurable change. The significant scatter of results observed previously (sections 3.1 and 3.3) was also observed in the 2016 results, and no different conclusions could be drawn. Furthermore, the physical parameters did not provide any additional information concerning previous conclusions. Thus, the focus is on the soil's compressibility and permeability, particularly significant to the Soulou spoil heap, that suffers from long-term consolidation and cannot be exploited until consolidation settlements have diminished to acceptable levels.

The evolution of the coefficient of permeability, constrained modulus, and compression index with depth is presented in Figure 9; for the coefficient of permeability and the constrained modulus, a reference vertical stress of $100 \mathrm{kPa}$ is used. Four sets of points are employed: samples are separated into silts and clays for each investigation program (2010 and 2016). This distinction is necessary for this section as they present different orders of magnitude for the coefficient of permeability (k) and, thus, they are separated to establish a more rational comparison basis. The data indicate that $\mathrm{k}$ decreases with time, as expected, for both silts and clays; after only six years, k has remarkably decreased by about one order of magnitude. It is probable that as consolidation advances, excess pore pressures tend to decrease and void spaces decrease in size, making it less permeable. This decrease of 
permeability over time could lead to larger consolidation times than initially expected. Permeability testing using other devices (e.g. triaxial device) could have been employed to support this trend further; however, these tests were not conducted during the geotechnical investigation.

In agreement with this hypothesis, the constrained modulus $E_{s}$ tends to increase with time; based on the 2010 investigation program $E_{s}$ ranged between 1 and $4 \mathrm{MPa}$, while on the 2016 data it varies between 3 and 7 MPa (Figure 9(b)). Since consolidation settlements have advanced to a certain degree, water outflow has led to a decrease in spoil compressibility, thus creating a stiffer material. As expected, $E_{s}$ is not dependent on soil classification as clay or silt, but it has a clear tendency for increase even for the relatively small-time interval of six years. Finally, the compression index $c_{c}$ presented in Figure 9(c) does not demonstrate any significant difference between the two investigations. It is possible that the evolution of $c_{c}$ during these six years is minor and not reflected in the measurements.

Overall, only a small number of the spoil material parameters changed significantly over six years; those parameters are mainly related to consolidation, given that this is an ongoing process. This continuing consolidation poses a challenge for analysis and simulation where the critical question regarding the required time for the ultimate termination of consolidation settlements remains unanswered.

\section{Conclusions}

Spoil materials from coal or lignite mines are significant because of the vast areas they cover and their potential for future exploitation. Nevertheless, they have received relatively little attention in characterizing their geotechnical properties. The geotechnical characterization of spoil materials involves high variability levels due to their relatively random deposition process, creating challenging engineering design conditions. In the present work, a systematic effort was made to classify and characterize the spoil material of a significant Greek spoil heap, quantifying its variable geotechnical parameters and contrasting results with those of common soils.

A database of results from extensive lab testing on samples from the spoil heap was compiled and evaluated. Index properties, physical properties, and shear strength and compressibility parameters were statistically analyzed to provide mean, median, and characteristic values and coefficients of variation. This statistical approach was employed to quantify the variability of the spoil material in a 
simplified manner, providing values for geotechnical design and an approach to examine similar cases in the future. Based on these results, a more informed analysis can be made to evaluate the spoil heap's exploitation and analyze possible future design scenarios.

A major conclusion was that the spoil heap's body is highly heterogeneous, while a significant outcome was the quantification of this variability, clearly indicating that the variability of geotechnical parameters of spoil exceeds that of natural soils. This difference is related mainly to the extraction and deposition processes related to the construction of the heap. This heterogeneity and geotechnical compared to sands and clays.

Furthermore, cross-correlations and dependencies between the different geotechnical parameters were examined. A cross-correlation was shown to exist between the shear strength parameters of friction angle and cohesion; however, it was impossible to correlate shear strength parameters with any other parameter. On the contrary, the loading and unloading compression indices were correlated parameter variability must be considered in design. The spoil heap's characteristic material was identified as an intermediate material classified as high plasticity silt, which can be problematic

to physical parameters such as Liquid Limit and Liquidity Index, consistent with more common soil materials. Additionally, linear relations were proposed, mainly as boundaries, for the spoil material that could be practically used. Nevertheless, notice that spoil variability is high, and due caution should be exercised while using them.

Finally, the effect of time was evaluated based on two different investigations that took place six years apart. The constrained modulus increased slightly, while the compression index $c_{c}$ was essentially unchanged. The permeability decreased by about one order of magnitude.

This work has demonstrated and quantified the substantial heterogeneity and variability of geotechnical parameters of a significant spoil heap in Greece. It is an effort to quantify this geotechnical uncertainty and inform the analysis of spoil behavior. It is underlined that the properties of the coal spoils are extremely variable and the results of the current study while showing exciting and promising trends, still have limitations. However, the integration of the geotechnical variability of spoils within numerical computations, and the implementation of reliability concepts within engineering evaluations based on the above discussion, would lead to more reasonable predictions than conventional methods. 


\section{Data Availability Statement}

Some data that support the findings of this study are available from the corresponding author upon reasonable request (analyzed results based on extended geotechnical investigation).

Some data generated or used during the study are proprietary or confidential in nature and may only be provided with restrictions (raw data of the geotechnical investigation).

\section{Acknowledgements}

This work has received funding from the European Union's Research Fund for Coal and Steel under the projects “SLOPES - Smarter Lignite Open Pit Engineering Solutions” grant agreement No RFCR-CT-201500001 and "SUMAD - Sustainable Use of Mining Waste Dumps" grant agreement No 847227. Financial assistance by the European Commission is greatly appreciated. The authors are also thankful to the Public Power Corporation (P.P.C.) for kindly providing raw data based on which this study was performed.

\section{Supplemental Materials}

Figs. S1-S9 and Tables S1 and S2 are available online in the ASCE Library (ascelibrary.org) 


\section{References}

[1] Alves Dias, P., Kanellopoulos, K., Medarac, H., Kapetaki, Z., Miranda-Barbosa, E., Shortall, R., Czako, V., Telsnig, T., Vazquez-Hernandez, C., Lacal Arántegui, R., Nijs, W., Gonzalez Aparicio, I., Trombetti, M., Mandras, G., Peteves, E., and Tzimas, E. 2018. EU coal regions: opportunities and challenges ahead EUR 29292 EN, Luxembourg: Publications Office of the European Union.

[2] ASTM C136 2006. "Standard Test Method for Sieve Analysis of Fine and Coarse Aggregates." ASTM International, West Conshohocken.

[3] ASTM D854-14 2014. "Standard Test Methods for Specific Gravity of Soil Solids by Water Pycnometer." ASTM International, West Conshohocken.

[4] ASTM D2166-66 1966. "Standard Test Method for Unconfined Compressive Strength of Cohesive Soil." ASTM International, West Conshohocken.

[5] ASTM D2216 2010. "Standard Test Methods for Laboratory Determination of Water (Moisture) Content of Soil and Rock by Mass." ASTM International, West Conshohocken.

[6] ASTM D2435-80 1980. "Standard Test Methods for One-Dimensional Consolidation Properties of Soils Using Incremental Loading." ASTM International, West Conshohocken.

[7] ASTM D2850-82 1982. "Standard Test Method for Consolidated Undrained Triaxial Compression Test for Cohesive Soils." ASTM International, West Conshohocken.

[8] ASTM D4318-83 1983. "Standard Test Methods for Liquid Limit, Plastic Limit, and Plasticity Index of Soils." ASTM International, West Conshohocken.

[9] Baecher, G. B., and Christian, J. T. 2003. Reliability and Statistics in Geotechnical Engineering, Chichester, UK: John Wiley \& Sons.

[10] Bell, F. G., and Donnelly, L. J. 2006. Mining and its Impact on the Environment, New York: Taylor \& Francis.

[11] Benson, C. H. 1993. "Probability Distributions for Hydraulic Conductivity of Compacted Soil Liners". Journal of Geotechnical Engineering, 119(3), 471-486.

[12] Bian, Z., Miao, X., Lei, S., Chen, S.-e., Wang, W., and Struthers, S. 2012. "The Challenges of Reusing Mining and Mineral-Processing Wastes". Science, 337(6095), 702-703.

[13] Cadierno, J. F., Romero, M. I. G., Valdés, A. J., del Pozo, J. M. M., González, J. G., Robles, D. R., and Espinosa, J. V. 2014. "Characterization of Colliery Spoils in León: Potential Uses in Rural Infrastructures". Geotechnical and Geological Engineering, 32(2), 439-452.

[14] Cherubini, C. 2000. "Reliability evaluation of shallow foundation bearing capacity on c', $\phi$ ' soils". Canadian Geotechnical Journal, 37(1), 264-269.

[15] Dawson, R. F., Morgenstern, N. R., and Stokes, A. W. 1998. "Liquefaction flowslides in Rocky Mountain coal mine waste dumps". Canadian Geotechnical Journal, 35(2), 328-343.

[16] Euracoal 2018. "EURACOAL Market Report 1/2018 - 5/2018." European Association for Coal and Lignite.

[17] Fityus, S., Robertson, H., Bradfield, L., and Simmons, J. 2014. "Unsaturated shear strength of coal mine spoil." In Proc., Unsaturated Soils: Research and Applications - Proceedings of the 6th International Conference on Unsaturated Soils, UNSAT 2014, 1335-1340.

[18] Harr, M. E. 1987. Reliability-Based Design in Civil Engineering, McGraw-Hill.

[19] Holtz, R. D., Kovacs, W. D., and Sheahan, T. C. 2010. An Introduction to Geotechnical Engineering, Englewood Cliffs, New Jersey: Prentice Hall.

[20] Işık, N. S. 2009. "Estimation of swell index of fine grained soils using regression equations and artificial neural networks". Scientific Research and Essays, 4(10), 1047-1056.

[21] Kavvadas, M., Roumpos, C., and Schilizzi, P. 2020. "Stability of Deep Excavation Slopes in Continuous Surface Lignite Mining Systems". Geotechnical and Geological Engineering, 38(1), 791-812. [22] Leonards, G. A. 1976. "Estimating Consolidation Settlements of Shallow Foundations on Overconsolidated Clay - Special Report 163." Transportation Research Board, National Research Council, Washington, DC 20418.

[23] Li, G., Cao, S., Li, Y., and Zhang, Z. 2016. "Load bearing and deformation characteristics of granular spoils under unconfined compressive loading for coal mine backfill". Advances in Materials Science and Engineering, 2016.

[24] Lumb, P. 1970. "Safety factors and the probability distribution of soil strength". Canadian Geotechnical Journal, 7(3), 225-242.

[25] Lumb, P. 1974. "Application of statistics in soil mechanics." Soil Mechanics: New Horizons., I. K. Lee, ed., 44-112, 221-239. 
[26] Masoudian, M. S., Zevgolis, I. E., Deliveris, A. V., Marshall, A. M., Heron, C. M., and Koukouzas, N. C. 2019. "Stability and characterisation of spoil heaps in European surface lignite mines: a state-of-theart review in light of new data". Environmental Earth Sciences, 78(16), 505.

[27] Means, R. E., and Parcher, J. V. 1963. Physical properties of soils, Columbus, Ohio: C.E. Merrill Books.

[28] Okagbue, C. O. 1984. "The geotechnical characteristics and stability of a spoil heap at a southwestern pennsylvania coal mine, U.S.A". Engineering Geology, 20(4), 325-341.

[29] Orr, T. L. L., and Farrell, E. R. 2000. Geotechnical Design to Eurocode 7, Springer.

[30] Poulsen, B., Khanal, M., Rao, A. M., Adhikary, D., and Balusu, R. 2014. "Mine Overburden Dump Failure: A Case Study". Geotechnical and Geological Engineering, 32(2), 297-309.

[31] Roumpos, C., Pavloudakis, F., Liakoura, A., Nalmpanti, D., and Arampatzis, K. 2018. "Utilisation of Lignite Resources within the Context of a Changing Electricity Generation Mix." In Proc., 10th Jubilee International Brown Coal Mining Congress, 355-365.

[32] Schneider, H. R. 1997. "Panel discussion: Definition and determination of characteristic soil properties." In Proc., Proceedings of the Fourteenth International Conference on Soil Mechanics and Foundation Engineering. Rotterdam [u.a.]: Balkema.

[33] Skarzyńska, K. M., and Michalski, P. 1998. "Filtration through hydraulic embankments made of colliery spoil: Model tests". Waste Management and Research, 16(3), 233-243.

[34] Skempton, A. W., and Jones, O. T. 1944. "Notes on the compressibility of clays". Quarterly Journal of the Geological Society, 100(1-4), 119-135.

[35] Steiakakis, E., Kavouridis, K., and Monopolis, D. 2009. "Large scale failure of the external waste dump at the "South Field" lignite mine, Northern Greece". Engineering Geology, 104(3-4), 269-279.

[36] Terzaghi, K., and Peck, R. B. 1967. Soil mechanics in engineering pratice, New York: John Wiley.

[37] Terzaghi, K., Peck, R. B., and Mesri, G. 1996. Soil Mechanics in Engineering Practice, New York: John Wiley \& Sons, $3^{\text {rd }}$ edition.

[38] Ulusay, R., Arikan, F., Yoleri, M. F., and Çağlan, D. 1995. "Engineering geological characterization of coal mine waste material and an evaluation in the context of back-analysis of spoil pile instabilities in a strip mine, SW Turkey". Engineering Geology, 40(1), 77-101.

[39] Ulusay, R., Çaglan, D., Arlkan, F., and Yoleri, M. F. 1996. "Characteristics of biplanar wedge spoil pile instabilities and methods to improve stability". Canadian Geotechnical Journal, 33(1), 58-79.

[40] USACE 1990. "Engineer Manual 1110-1-1904 Settlement Analysis." Engineering and Design, U.S. Army Corps of Engineers, Washington, DC.

[41] Wolff, T. F. 1985. "Analysis and design of embankment dam slopes: A probabilistic approach."PhD Dissertation, Purdue University, West Lafayette, IN, USA.

[42] Yucemen, M. S., Tang, W. H., and Ang, A.-S. 1973. "A probabilistic study of safety and design of earth slopes." Structural Research, University of Illinois, Urbana.

[43] Zevgolis, I. E. 2018. "Geotechnical characterization of mining rock waste dumps in central Evia, Greece". Environmental Earth Sciences, 77(16), 566.

[44] Zevgolis, I. E., Deliveris, A. V., and Koukouzas, N. C. 2018a. "Probabilistic design optimization and simplified geotechnical risk analysis for large open pit excavations". Computers and Geotechnics, 103, 153-164.

[45] Zevgolis, I. E., Koukouzas, N. C., Roumpos, C., Deliveris, A. V., and Marshall, A. M. 2018b. "Evaluation of geotechnical property variability: the case of spoil material from surface lignite mines." In Proc., 5th International Civil Protection Conference - SafeKozani 2018. Kozani, Greece: SafeGreece. 
Fig. 1. Variation of (a) effective friction angle $\phi^{\prime}$ and (b) effective cohesion $c^{\prime}$ with depth

Fig. 2. Statistical distributions of (a) Liquid Limit (LL) and (b) Plastic Limit (PL)

Fig. 3. Statistical distributions of (a) effective friction angle $\left(\phi^{\prime}\right)$ and (b) compression index ( $\left.c_{c}\right)$

Fig. 4. Consolidated undrained triaxial test results on characteristic spoil samples: (a) deviatoric stress and (b) pore pressure, versus vertical axial strain $\varepsilon_{a}$

Fig. 5. 1D consolidation test results on characteristic spoil samples: (a) constrained modulus $E_{s}$ and (b) void ratio e during compression-recompression, versus vertical effective stress $\sigma_{v}{ }^{\prime}$

Fig. 6. (a) Strong negative linear correlation between drained friction angle and cohesion and (b) variance of friction angle $\phi^{\prime}$ with Plasticity Index PI

Fig. 7. General dependency between $c_{c}$ and $c_{r}$

Fig. 8. Evaluation of (a) compression index $c_{c}$ and (b) recompression index $c_{r}$ with respect to Liquid Limit Fig. 9. (a) Coefficient of permeability, (b) constrained modulus and (c) compression index with depth; separation between silts and clays and comparison of parameters for boreholes with a 6 year time interval 
Table 1. Index and physical properties for Soulou spoil heap

\begin{tabular}{|c|c|c|c|c|c|c|c|c|c|c|c|}
\hline \multirow[t]{2}{*}{ Parameter } & \multicolumn{3}{|c|}{ Grain size (\%) } & \multicolumn{5}{|c|}{$\begin{array}{l}\text { Moisture content and } \\
\text { Atterberg Limits (\%) }\end{array}$} & \multirow{2}{*}{$\begin{array}{c}\gamma \\
\left(\mathrm{kN} / \mathrm{m}^{3}\right)\end{array}$} & \multirow{2}{*}{$\begin{array}{c}\gamma_{d} \\
\left(k N / m^{3}\right)\end{array}$} & \multirow{2}{*}{$\begin{array}{l}\mathrm{G}_{\mathrm{s}} \\
(-)\end{array}$} \\
\hline & Gravels & Sands & Fines & w & $\mathrm{LL}$ & PL & $\mathrm{PI}$ & $\mathrm{LI}$ & & & \\
\hline $\mathrm{n}$ & 128 & 128 & 128 & 132 & 104 & 104 & 104 & 104 & 129 & 129 & 65 \\
\hline$\mu$ & 11 & 33 & 57 & 39 & 51 & 34 & 16 & 0.3 & 16.9 & 12.6 & 2.55 \\
\hline$\tilde{\mu}$ & 3 & 31 & 61 & 37 & 53 & 56 & 15 & 0.3 & 16.5 & 11.9 & 2.57 \\
\hline$\sigma$ & 14 & 12 & 17 & 18 & 12 & 12 & 7 & 0.7 & 2.2 & 3.1 & 0.15 \\
\hline $\operatorname{cov}(\%)$ & 133 & 38 & 30 & 45 & 24 & 34 & 44 & 253 & 13 & 24 & 6 \\
\hline $\min$ & 0 & 6 & 9 & 9 & 22 & 16 & 3 & -1.8 & 12.6 & 7.0 & 2.20 \\
\hline $\max$ & 60 & 91 & 94 & 81 & 84 & 62 & 37 & 1.9 & 22.3 & 20.3 & 2.80 \\
\hline range & 60 & 84 & 85 & 72 & 62 & 46 & 34 & 3.7 & 9.7 & 13.2 & 0.60 \\
\hline
\end{tabular}

$\mathrm{n}$ : population, $\mu$ : mean value, $\tilde{\mu}$ : median value, $\sigma$ : standard deviation, COV: coefficient of variance w: water content, LL: Liquid Limit, PL: plastic limit, PI: Plasticity Index, LI: Liquidity Index, $\gamma$ : moist unit weight, $\gamma_{\mathrm{d}}$ : dry unit weight, $\mathrm{G}_{\mathrm{s}}$ : specific gravity

Table 2. Strength, compressibility, and permeability parameters for Soulou spoil heap

\begin{tabular}{|l|c|c|c|c|c|c|c|c|}
\hline Parameter & $\phi^{\prime}\left(^{\circ}\right)$ & $c^{\prime}(\mathrm{kPa})$ & $\mathrm{q}_{\mathrm{u}}(\mathrm{kPa})$ & $\mathrm{C}_{\mathrm{c}}(-)$ & $\mathrm{C}_{\mathrm{r}}(-)$ & $\begin{array}{c}\mathrm{E}_{\mathrm{s}}(\mathrm{MPa}) \\
\Delta \sigma_{\mathrm{v}}=50 \mathrm{kPa}\end{array}$ & $\begin{array}{c}\mathrm{k}(\mathrm{cm} / \mathrm{s}) \\
\sigma_{\mathrm{v}}=100 \mathrm{kPa}\end{array}$ & $\begin{array}{c}\mathrm{C}_{\mathrm{v}}\left(\mathrm{cm}^{2} / \mathrm{s}\right) \\
\sigma_{\mathrm{v}}=100 \mathrm{kPa}\end{array}$ \\
\hline $\mathrm{n}$ & 43 & 43 & 44 & 61 & 61 & 61 & 61 & 61 \\
\hline$\tilde{\mu}$ & 25.2 & 17.6 & 104 & 0.216 & 0.037 & 1.9 & $4.910^{-7}$ & $7.210^{-3}$ \\
\hline $\mathrm{X}_{\mathrm{k}}$ & 26.7 & 11.7 & 89 & 0.194 & 0.037 & 1.6 & $3.010^{-7}$ & $6.410^{-3}$ \\
\hline$\sigma$ & 21.8 & 8.3 & 64 & 0.176 & 0.030 & 1.35 & $2.4510^{-7}$ & $4.310^{-3}$ \\
\hline COV (\%) & 27 & 106 & 77 & 38 & 41 & 58 & $9.910^{-7}$ & $5.710^{-3}$ \\
\hline min & 8.2 & 0 & 5 & 0.064 & 0.013 & 0.6 & $1.210^{-8}$ & $2.310^{-4}$ \\
\hline max & 39.2 & 72.4 & 407 & 0.398 & 0.090 & 5.7 & $1.910^{-6}$ & $2.510^{-2}$ \\
\hline range & 31.0 & 72.4 & 402 & 0.334 & 0.077 & 5.1 & $0.610^{-2}$ & $0.910^{-2}$ \\
\hline
\end{tabular}

Table 3. Cross-correlation matrix (in terms of coefficients of linear correlation) of geotechnical properties for Soulou spoil heap

\begin{tabular}{|c|c|c|c|c|c|c|c|c|c|c|c|c|c|c|c|}
\hline$\rho$ & $L L$ & $P L$ & $P I$ & LI & $\gamma$ & $w$ & $e_{0}$ & $q_{u}$ & $C_{V}$ & $k$ & $E_{s}$ & $c_{c}$ & $c_{r}$ & $c^{\prime}$ & $\varphi^{\prime}$ \\
\hline$L L$ & & 0.82 & 0.36 & 0.35 & -0.72 & 0.80 & 0.81 & -0.27 & 0.26 & 0.12 & -0.13 & 0.41 & 0.52 & -0.24 & 0.23 \\
\hline$P L$ & 0.82 & & -0.23 & 0.32 & -0.80 & 0.85 & 0.87 & -0.31 & 0.32 & 0.27 & -0.24 & 0.50 & 0.40 & -0.27 & 0.37 \\
\hline$P I$ & 0.36 & -0.23 & & 0.08 & 0.09 & -0.02 & -0.08 & 0.07 & -0.10 & -0.24 & 0.19 & -0.15 & 0.19 & 0.09 & -0.24 \\
\hline$L I$ & 0.35 & 0.32 & 0.08 & & -0.55 & 0.72 & 0.64 & -0.26 & 0.07 & 0.03 & -0.28 & 0.40 & 0.49 & 0.14 & -0.29 \\
\hline$r$ & -0.72 & -0.80 & 0.09 & -0.55 & & -0.73 & -0.88 & 0.34 & -0.42 & -0.35 & 0.15 & -0.41 & -0.26 & 0.02 & -0.14 \\
\hline$w$ & 0.80 & 0.85 & -0.02 & 0.72 & -0.73 & & 0.93 & -0.19 & 0.09 & 0.05 & -0.16 & 0.45 & 0.46 & -0.05 & 0.10 \\
\hline$e_{0}$ & 0.81 & 0.87 & -0.08 & 0.64 & -0.88 & 0.93 & & -0.38 & 0.25 & 0.18 & -0.18 & 0.46 & 0.36 & -0.29 & 0.25 \\
\hline$q_{u}$ & -0.27 & -0.31 & 0.07 & -0.26 & 0.34 & -0.19 & -0.38 & & 0.10 & 0.09 & 0.18 & -0.11 & 0.05 & - & - \\
\hline$C_{v}$ & 0.26 & 0.32 & -0.10 & 0.07 & -0.42 & 0.09 & 0.25 & 0.10 & & 0.72 & 0.11 & 0.06 & - & -0.12 & 0.03 \\
\hline$k$ & 0.12 & 0.27 & -0.24 & 0.03 & -0.35 & 0.05 & 0.18 & 0.09 & 0.72 & & -0.41 & 0.52 & 0.19 & -0.26 & 0.07 \\
\hline$E_{s}$ & -0.13 & -0.24 & 0.19 & -0.28 & 0.15 & -0.16 & -0.18 & 0.18 & 0.11 & -0.41 & & -0.84 & -0.39 & 0.23 & 0.14 \\
\hline$c_{c}$ & 0.41 & 0.50 & -0.15 & 0.40 & -0.41 & 0.45 & 0.46 & -0.11 & 0.06 & 0.52 & -0.84 & & 0.50 & -0.29 & -0.07 \\
\hline$c_{r}$ & 0.52 & 0.40 & 0.19 & 0.49 & -0.26 & 0.46 & 0.36 & 0.05 & - & 0.19 & -0.39 & 0.50 & & -0.09 & -0.22 \\
\hline$c^{\prime}$ & -0.24 & -0.27 & 0.09 & 0.14 & 0.02 & -0.05 & -0.29 & - & -0.12 & -0.26 & 0.23 & -0.29 & -0.09 & & -0.74 \\
\hline$\varphi^{\prime}$ & 0.23 & 0.37 & -0.24 & -0.29 & -0.14 & 0.10 & 0.25 & - & 0.03 & 0.07 & 0.14 & -0.07 & -0.22 & -0.74 & \\
\hline
\end{tabular}




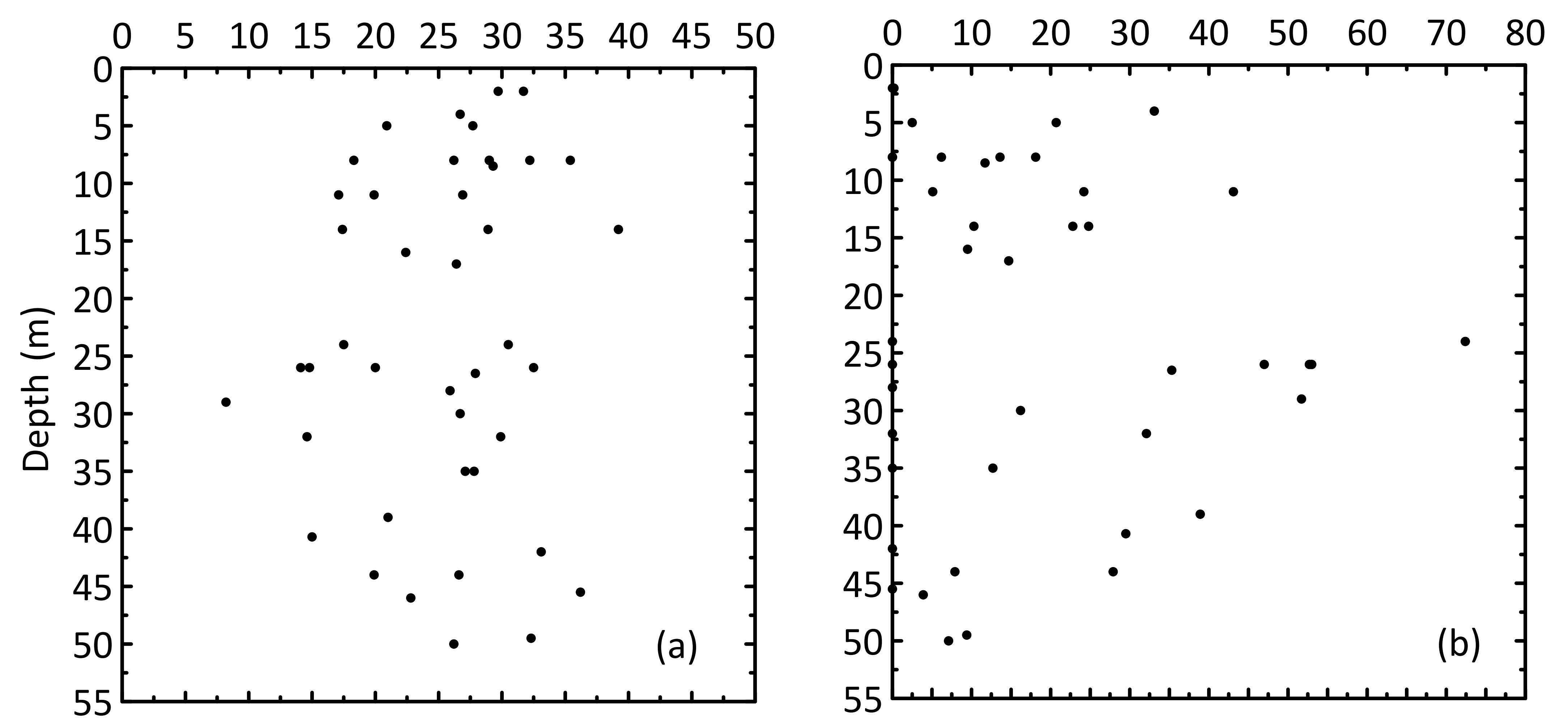




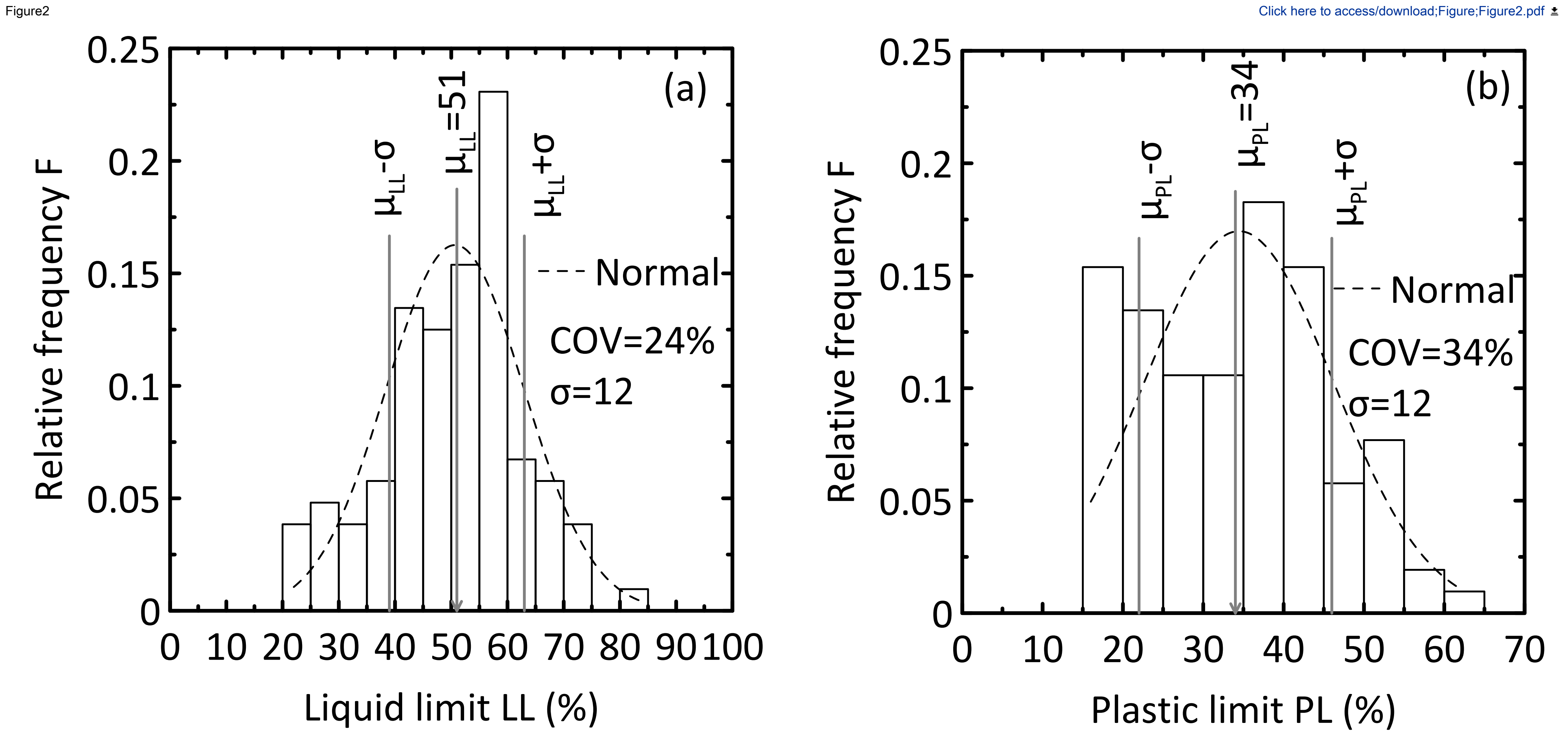




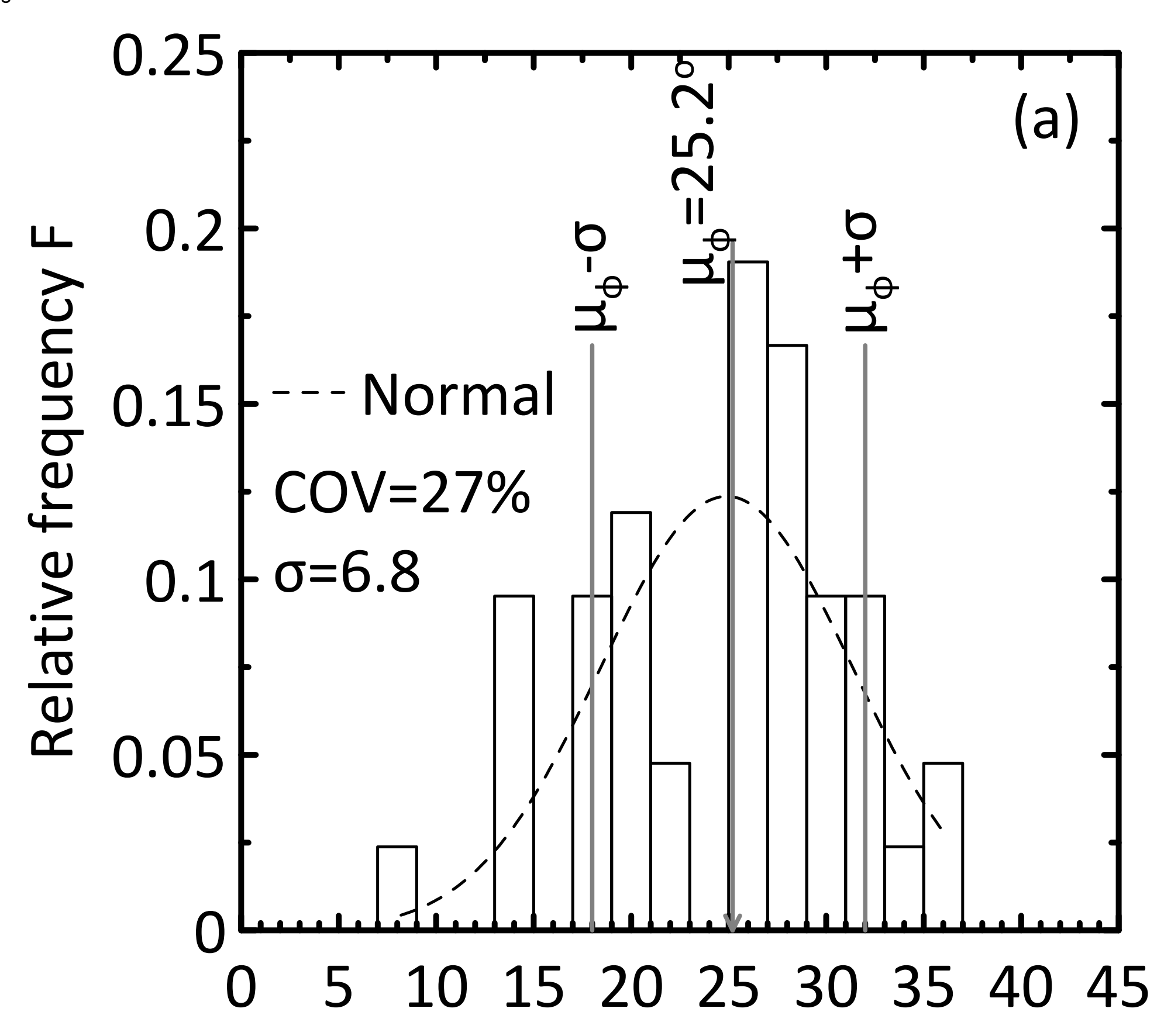

Effectice friction angle $\phi^{\prime}\left({ }^{\circ}\right)$

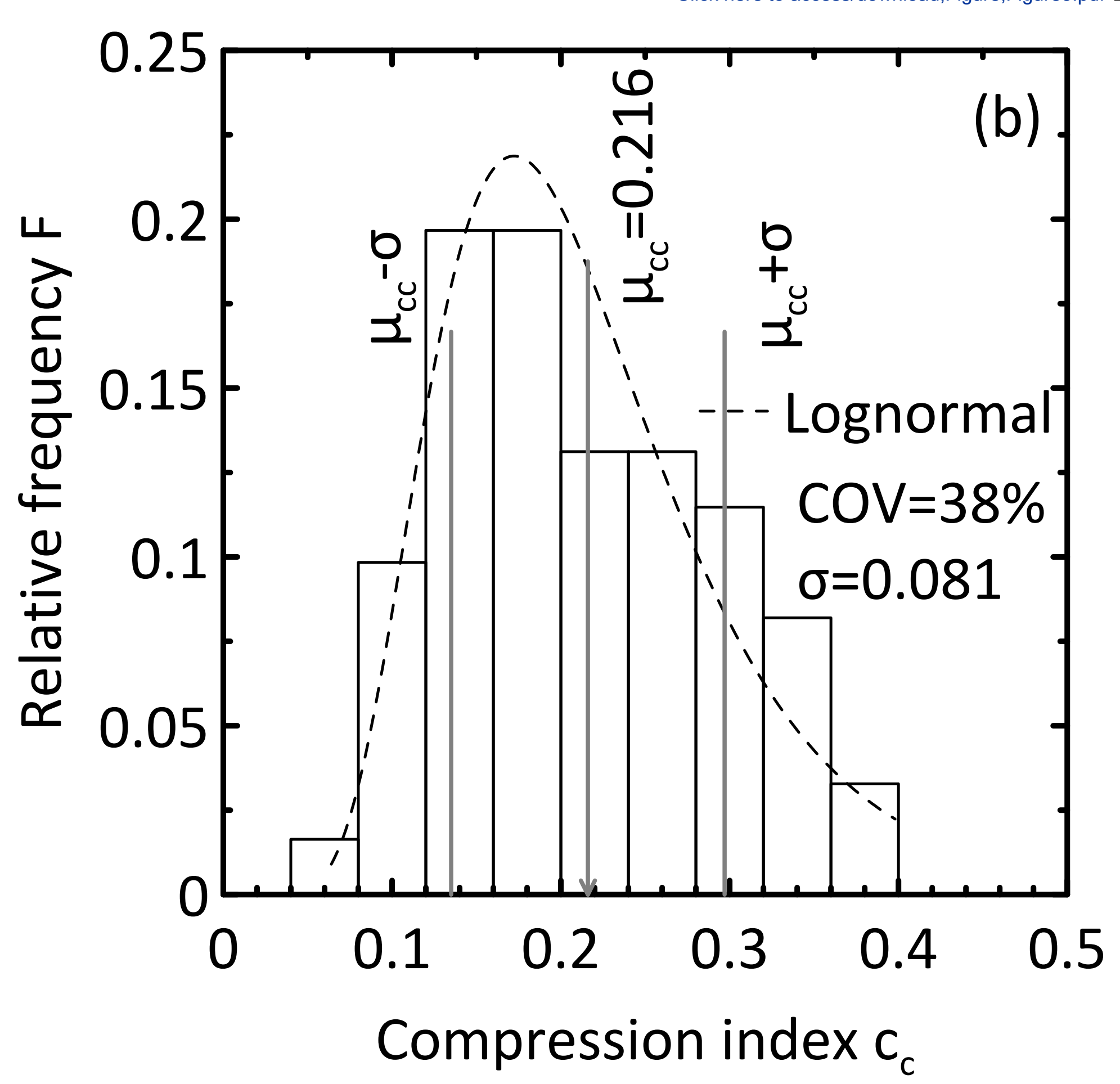



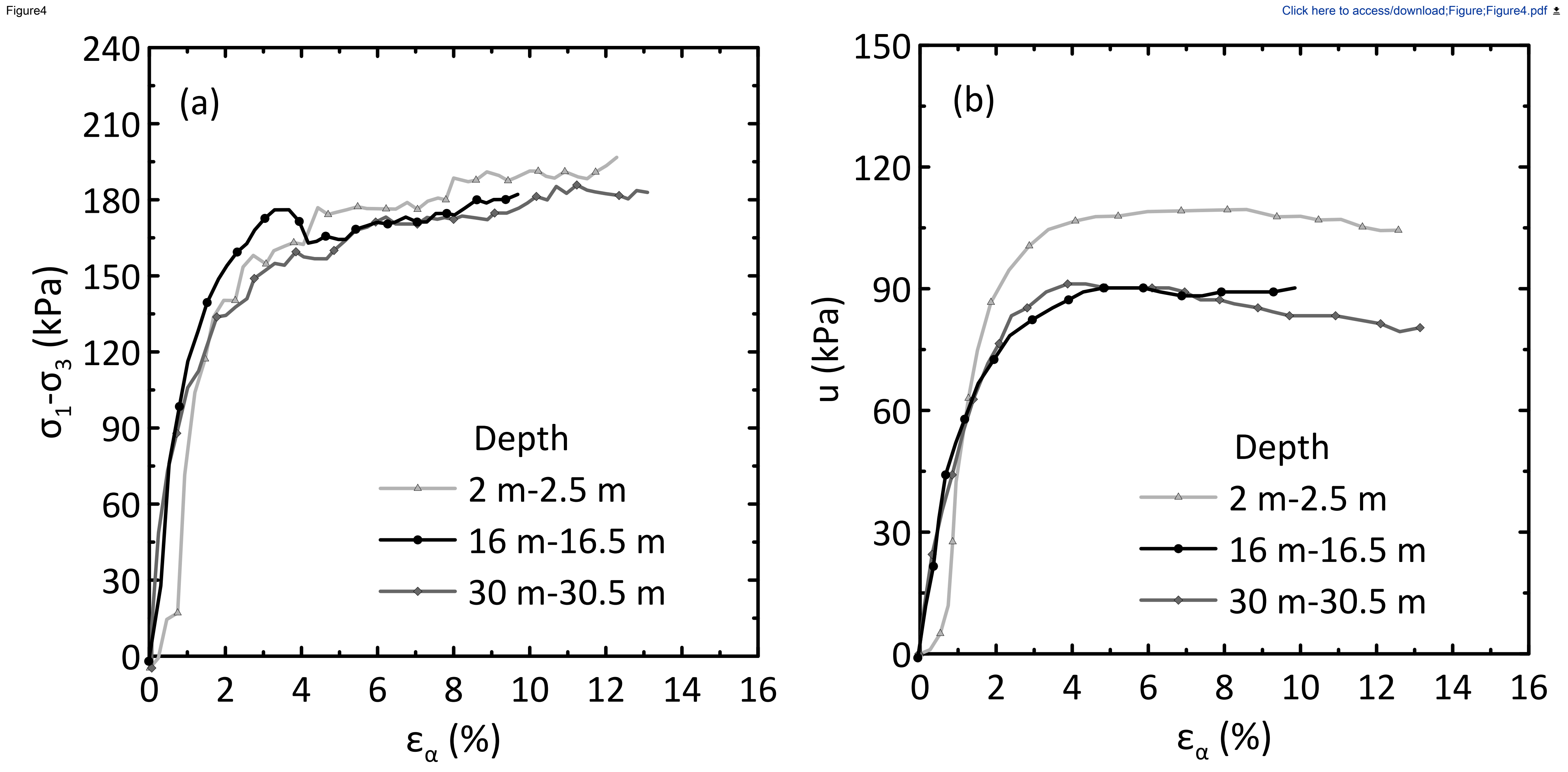


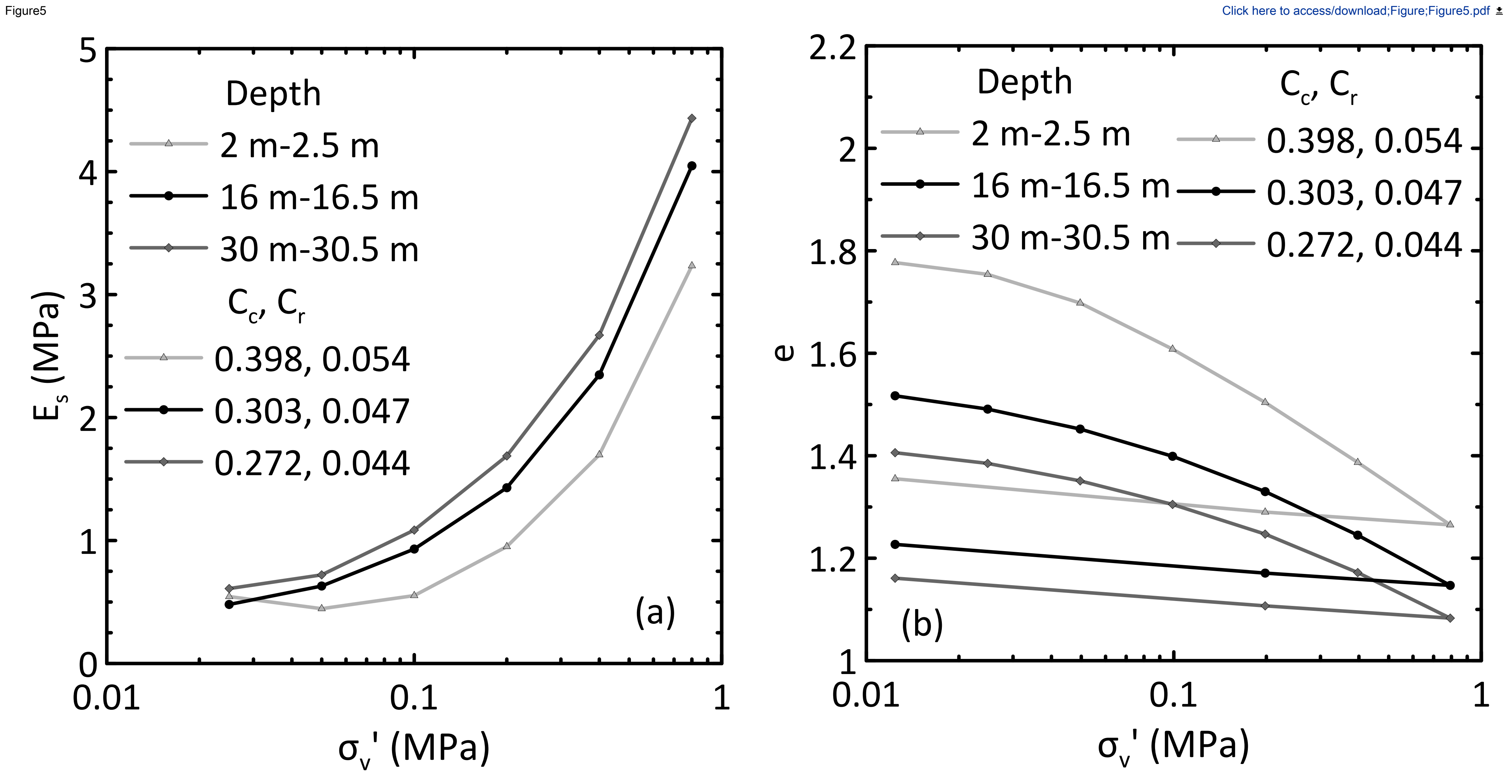




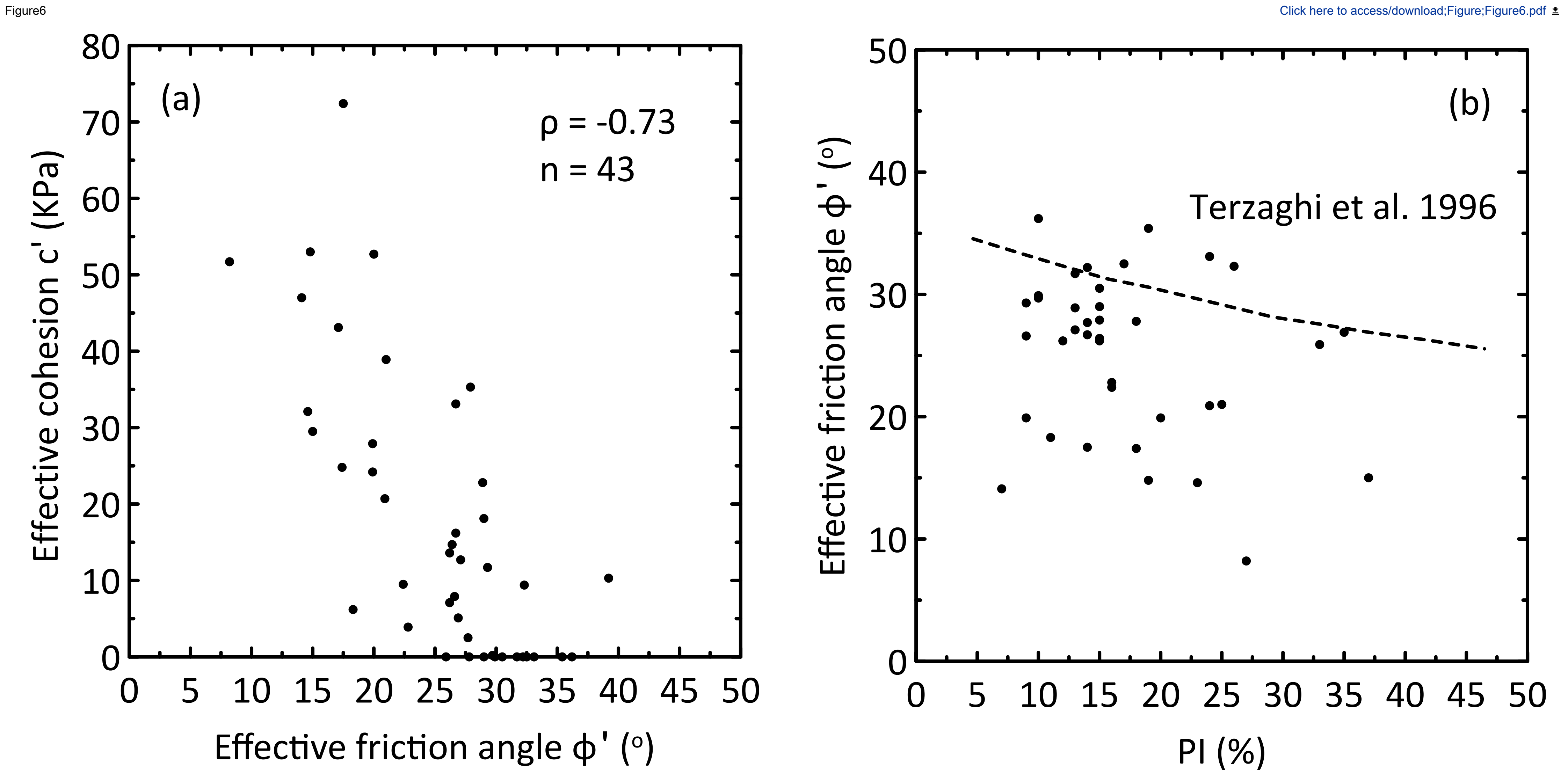




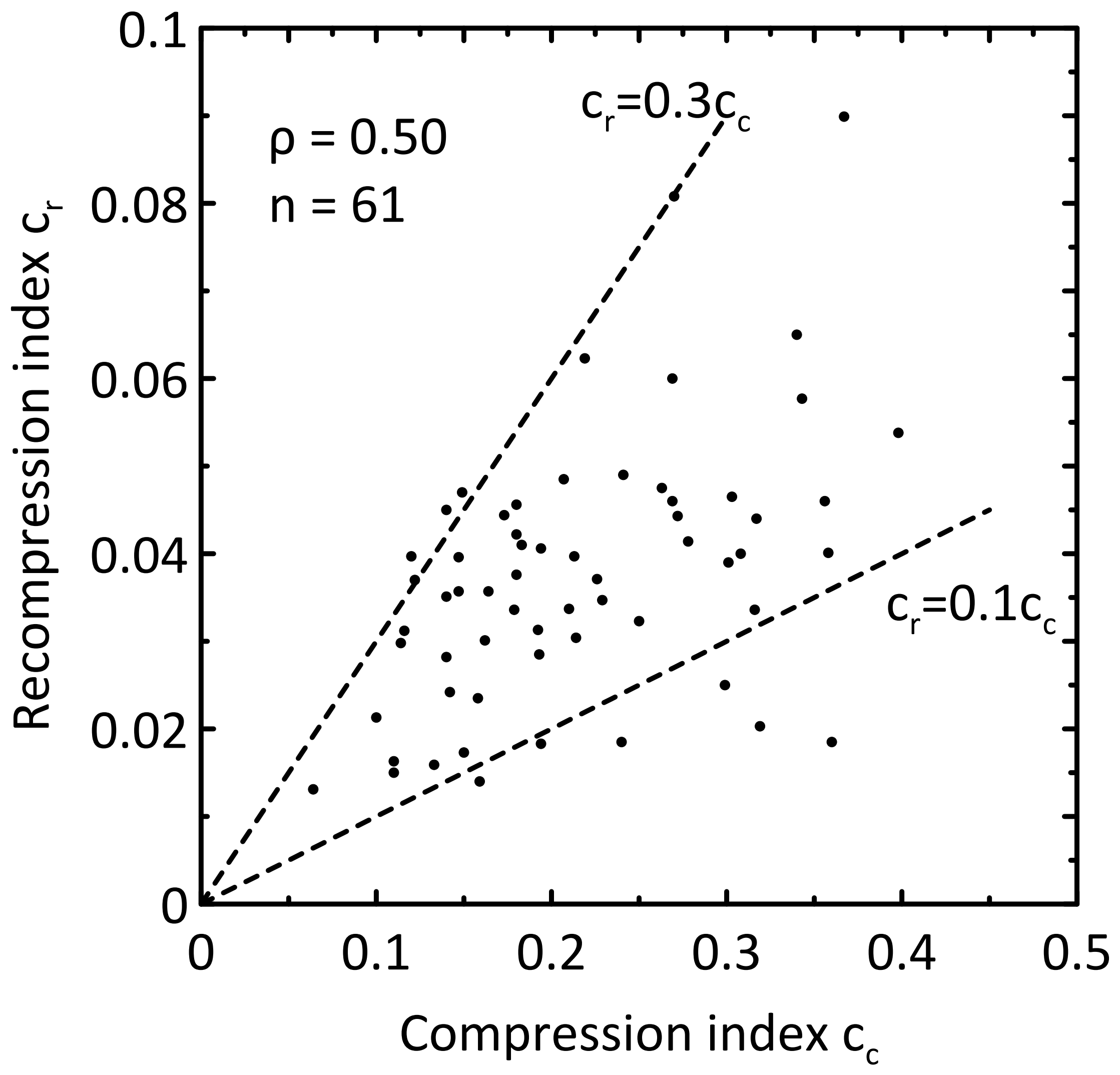



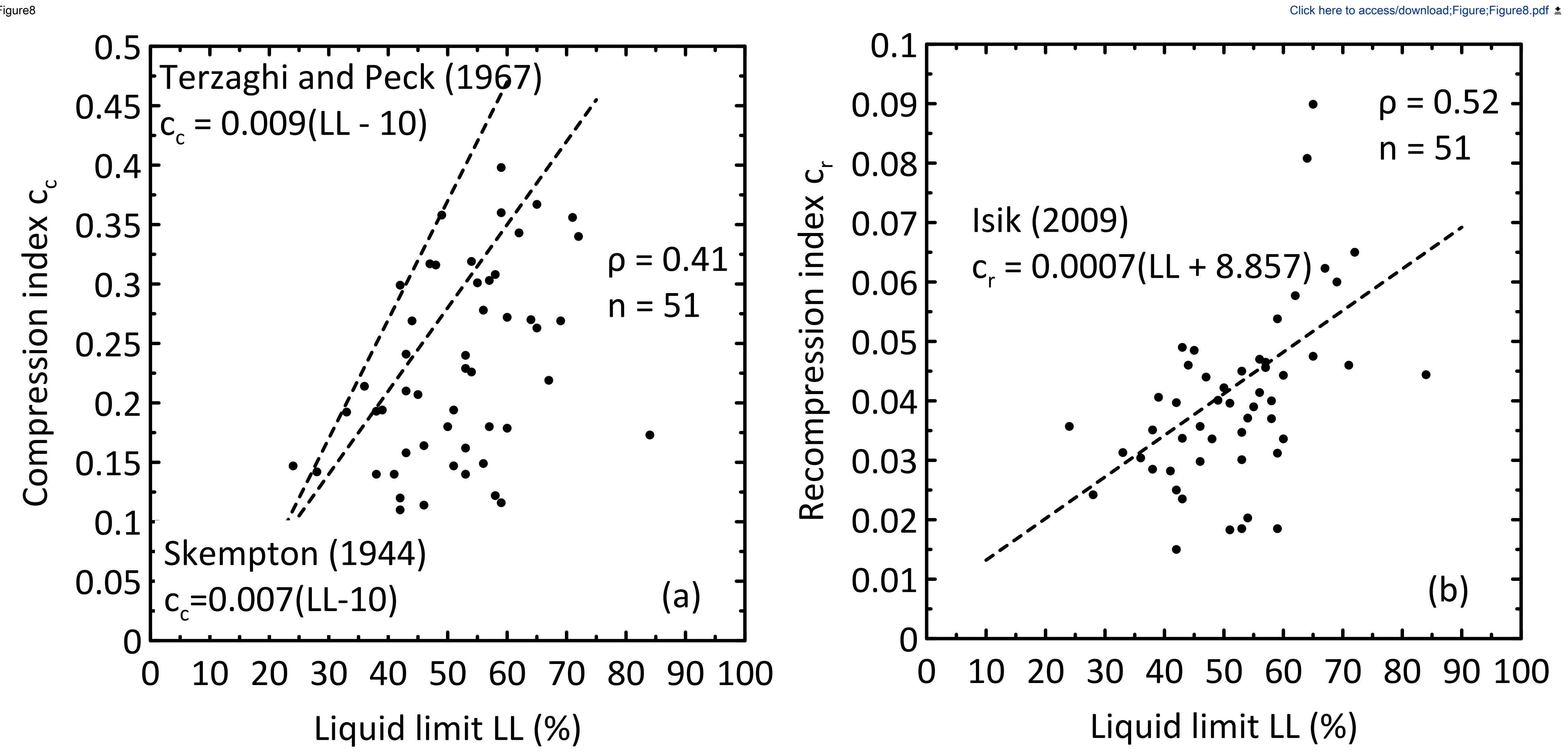
Coefficient of permeability $\mathrm{k}(\mathrm{cm} / \mathrm{s})$

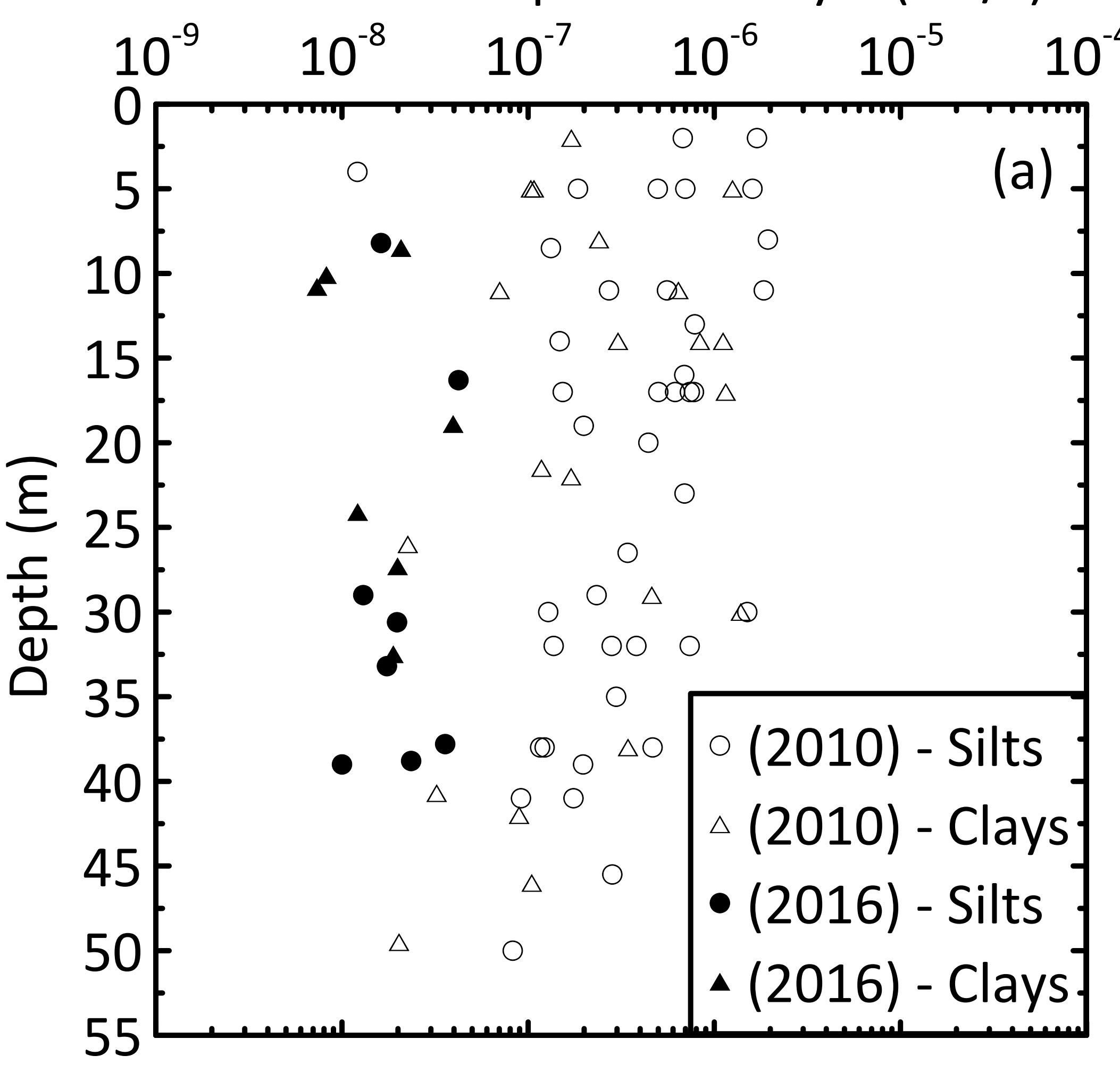

Constrained modulus $\mathrm{E}_{\mathrm{s}}(\mathrm{MPa})$

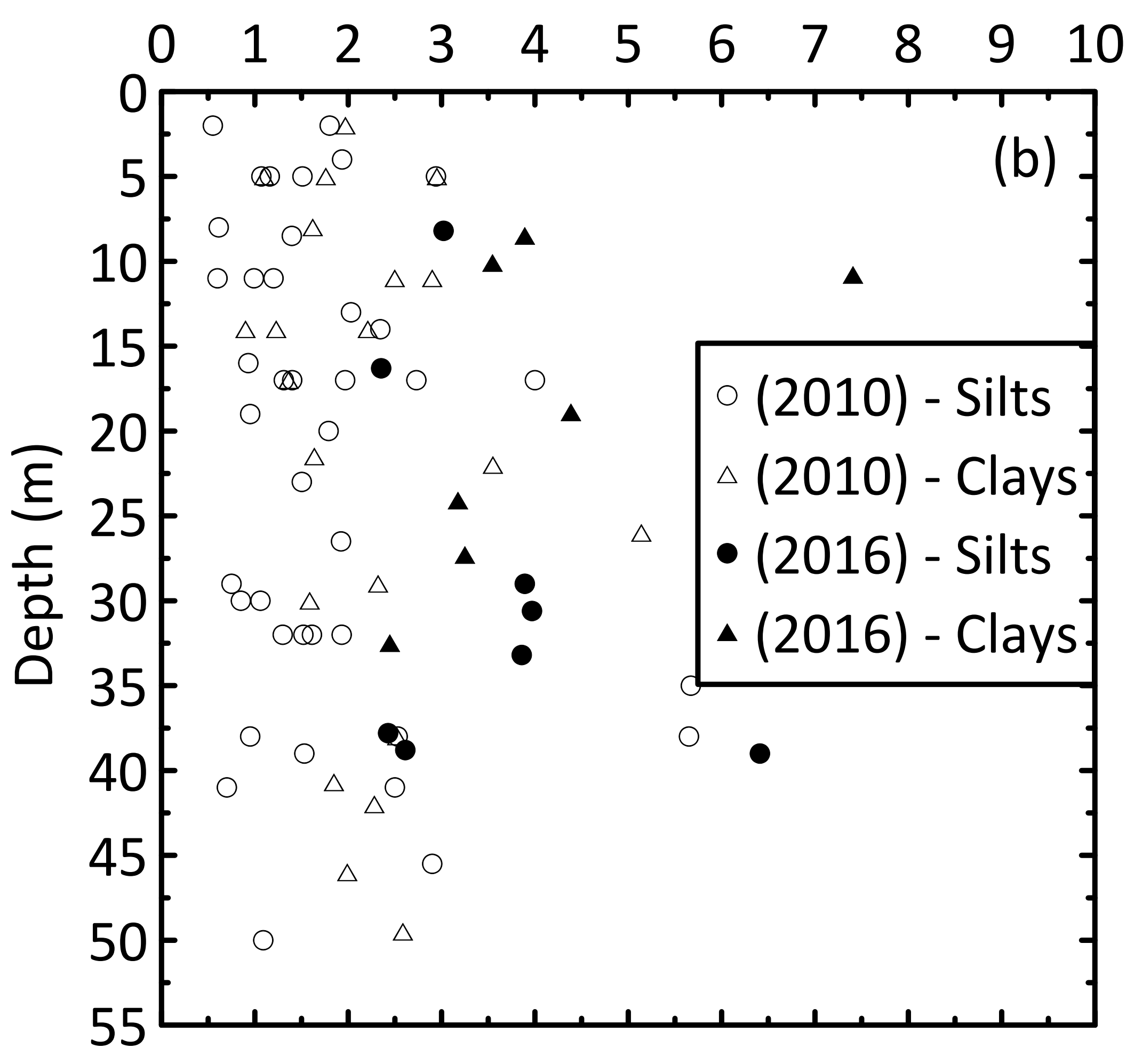

Compression index $c_{c}$

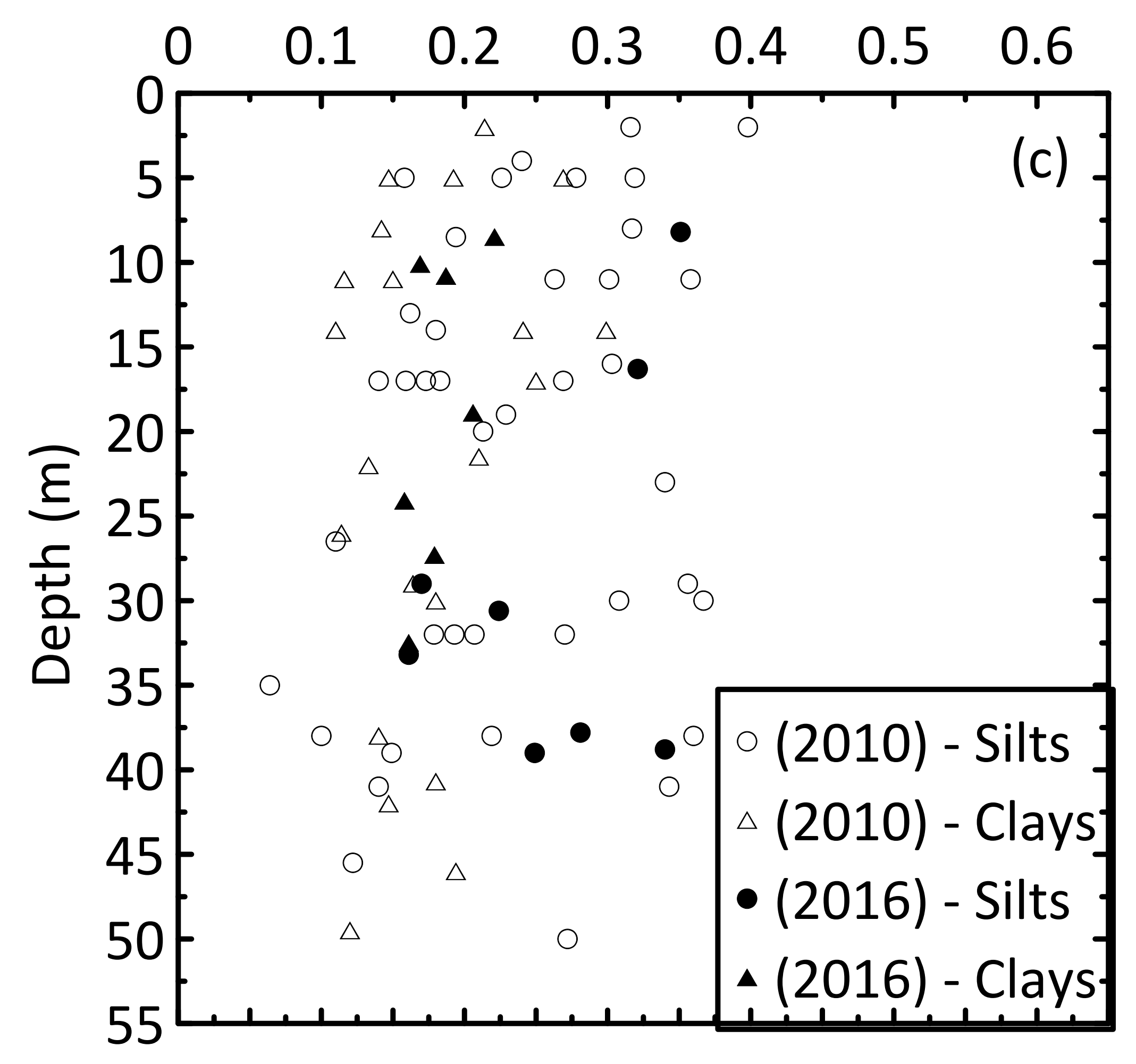




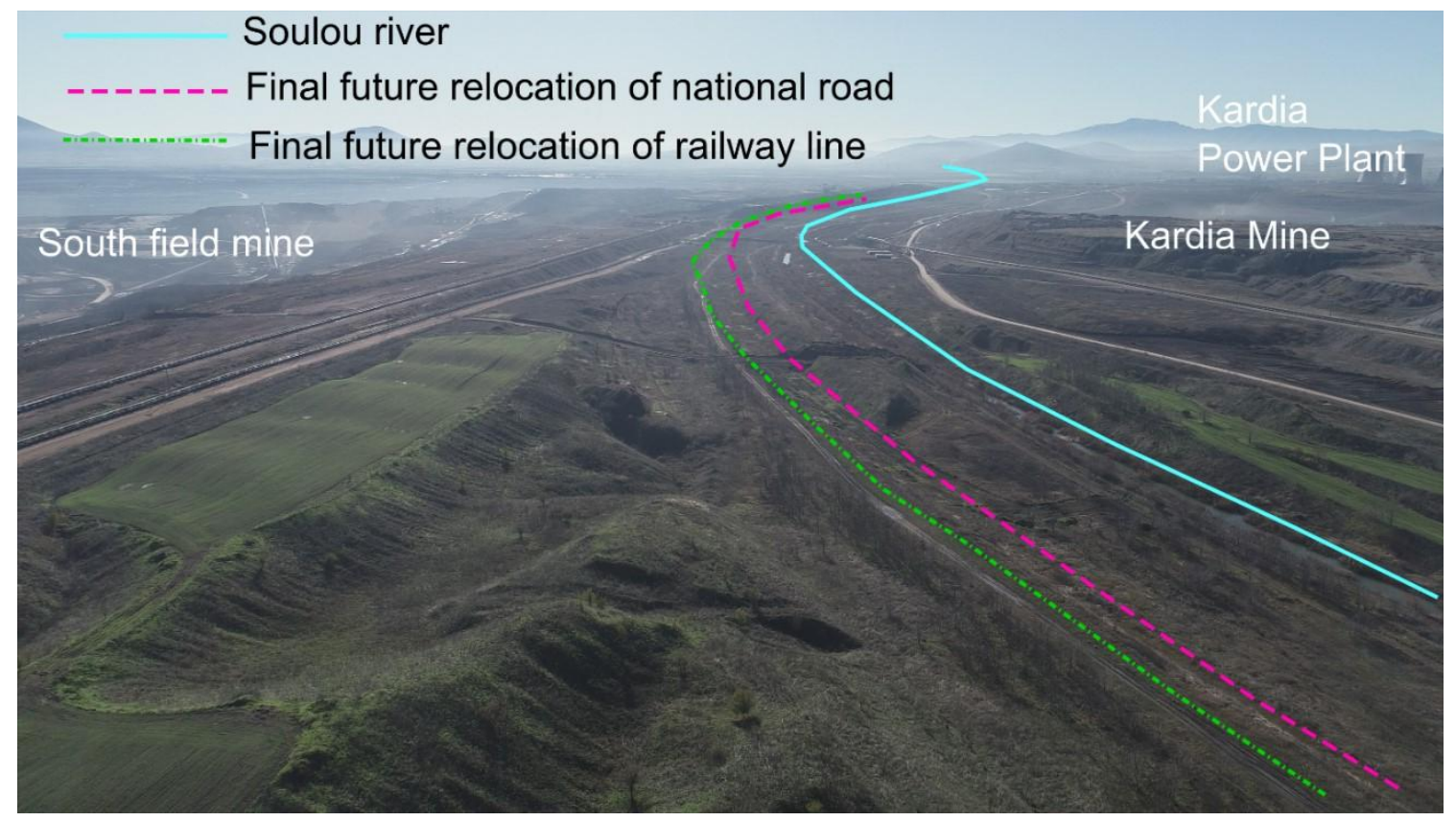

Fig. S1. View of the Soulou spoil heap

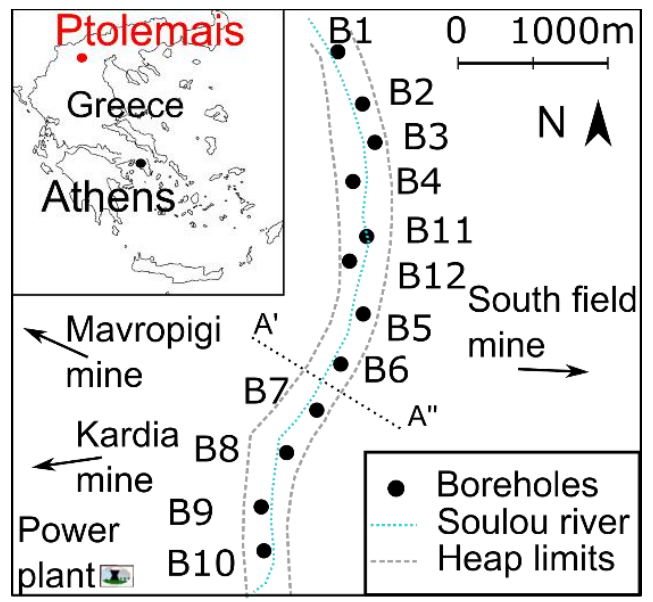

Fig. S2. Plan view of Soulou spoil heap showing borehole locations

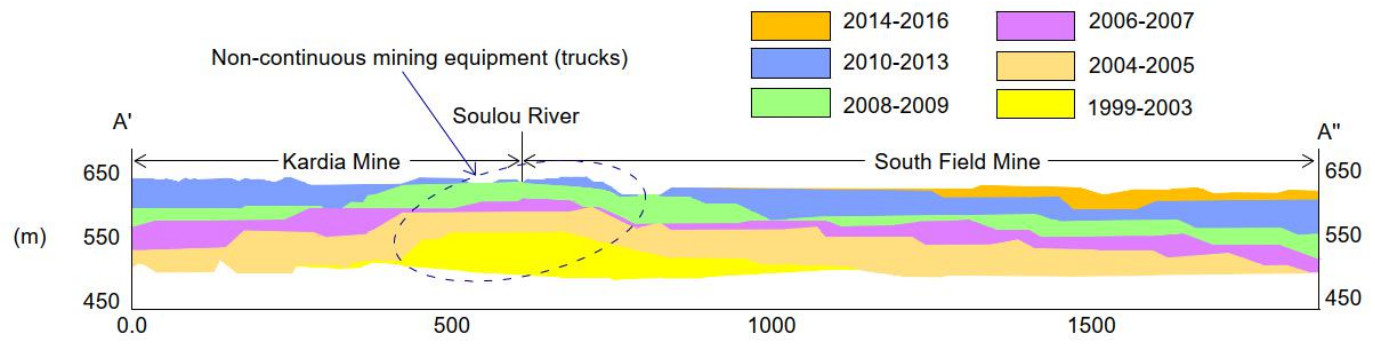

(m)

Fig. S3. Cross-section A'-A" (refer to Fig. S2) of the Soulou spoil heap 


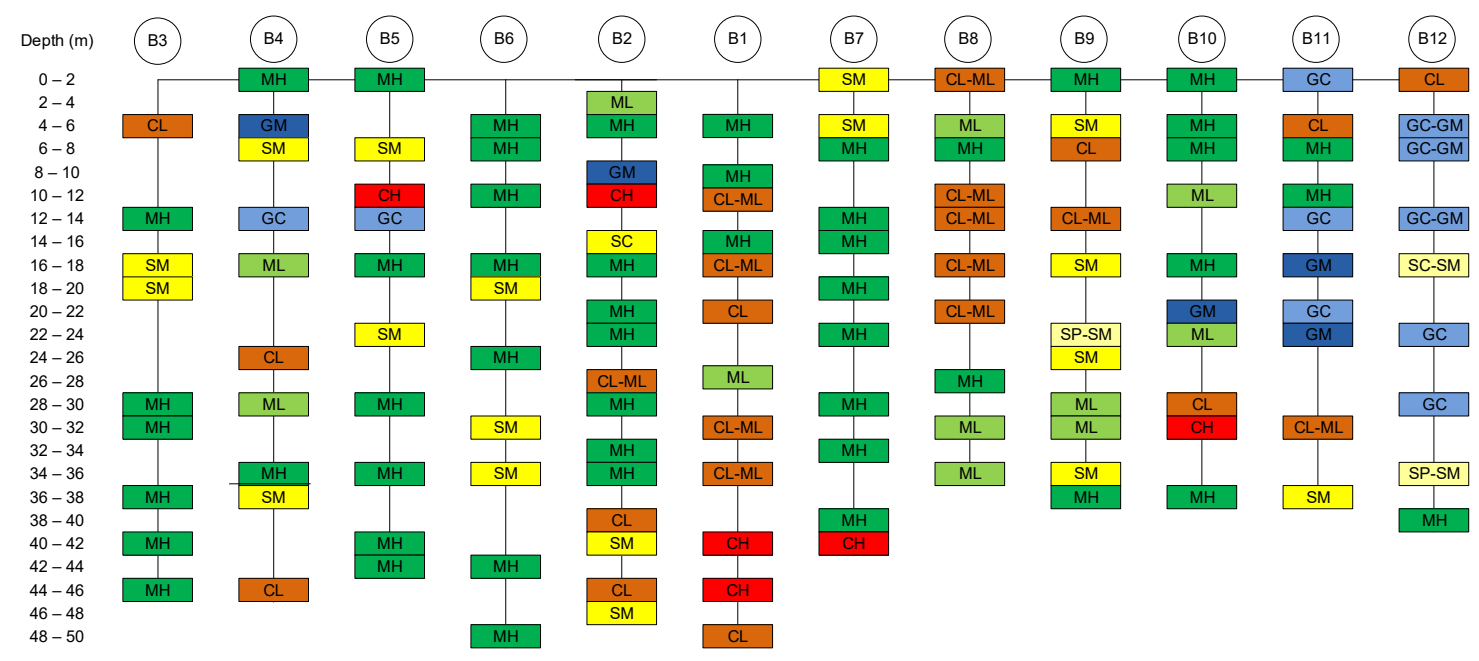

Fig. S4. Classification of spoil material (according to USCS) along the longitudinal axis of the spoil heap

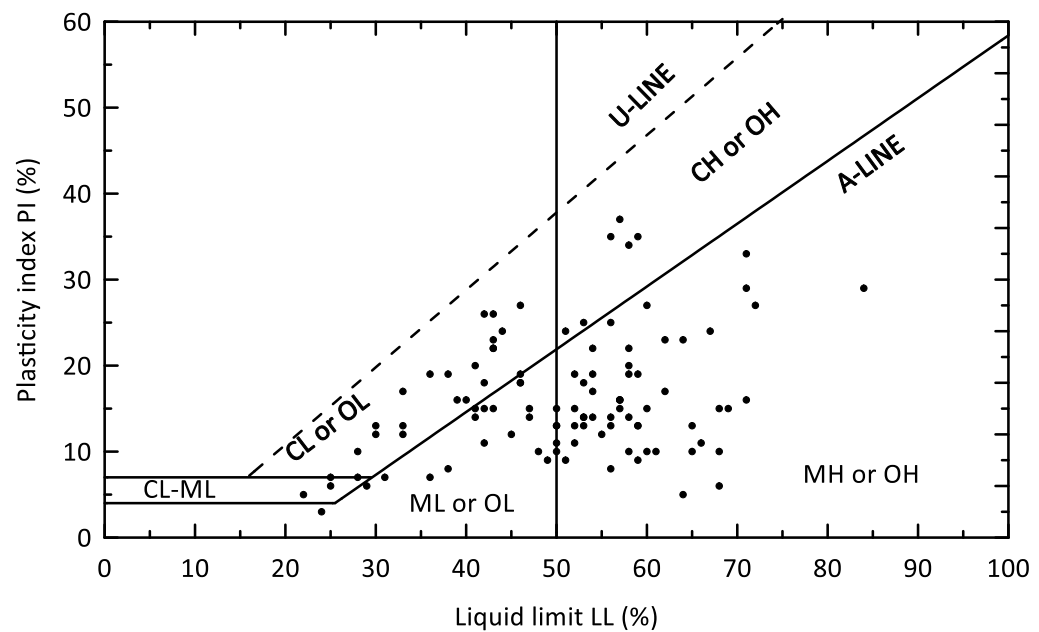

Fig. S5. Spoil material fine-grained fraction plasticity chart

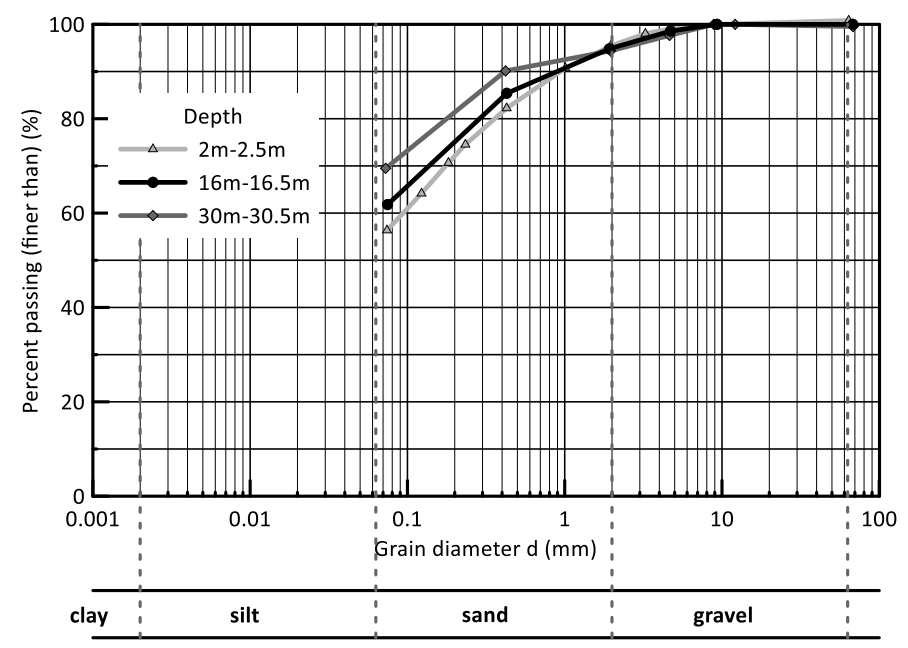

Fig. S6. Grain size distribution curves of three characteristic spoil samples 

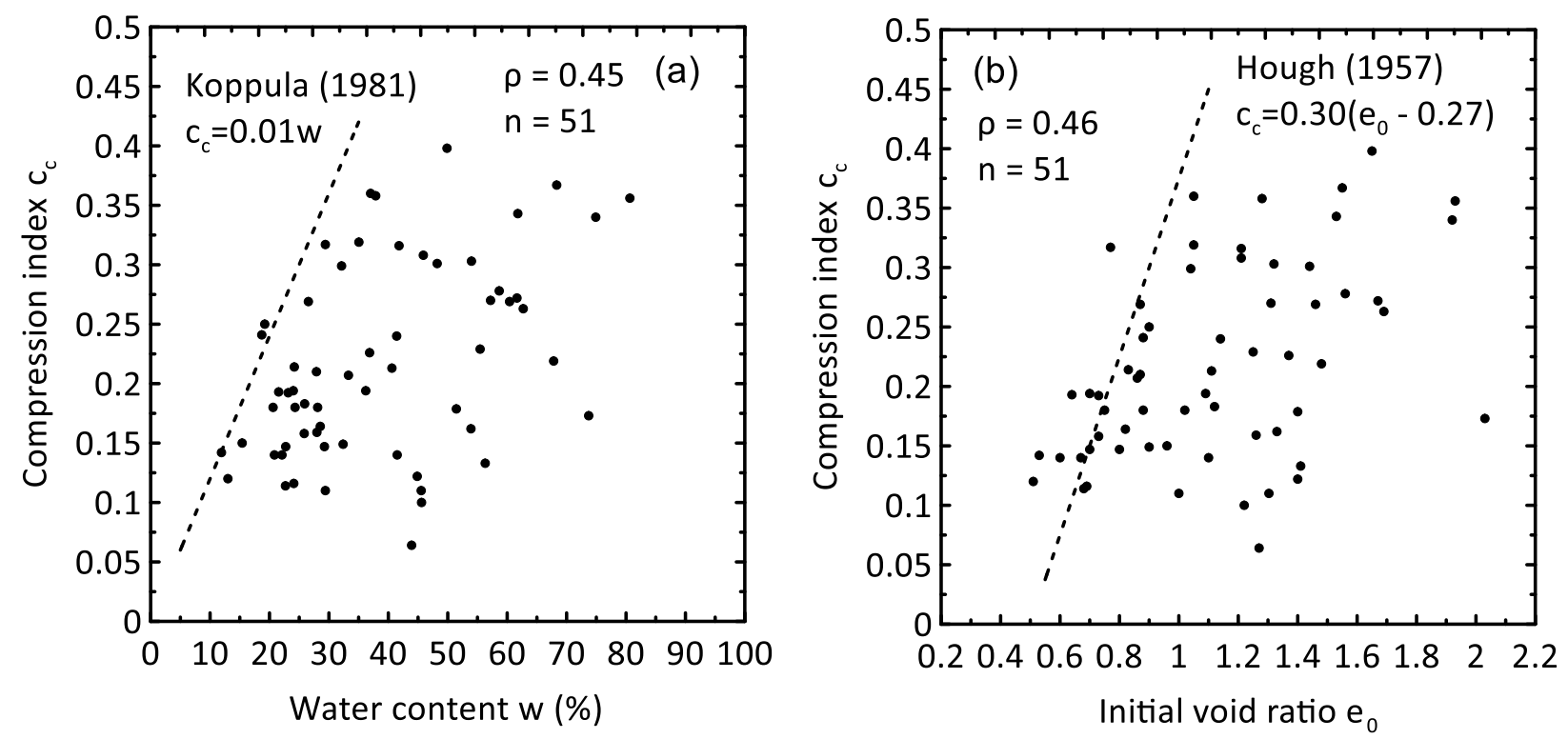

Fig. S7. Evaluation of compression index $c_{c}$ with $(a)$ water content, and (b) initial void ratio $\left(e_{0}\right)$
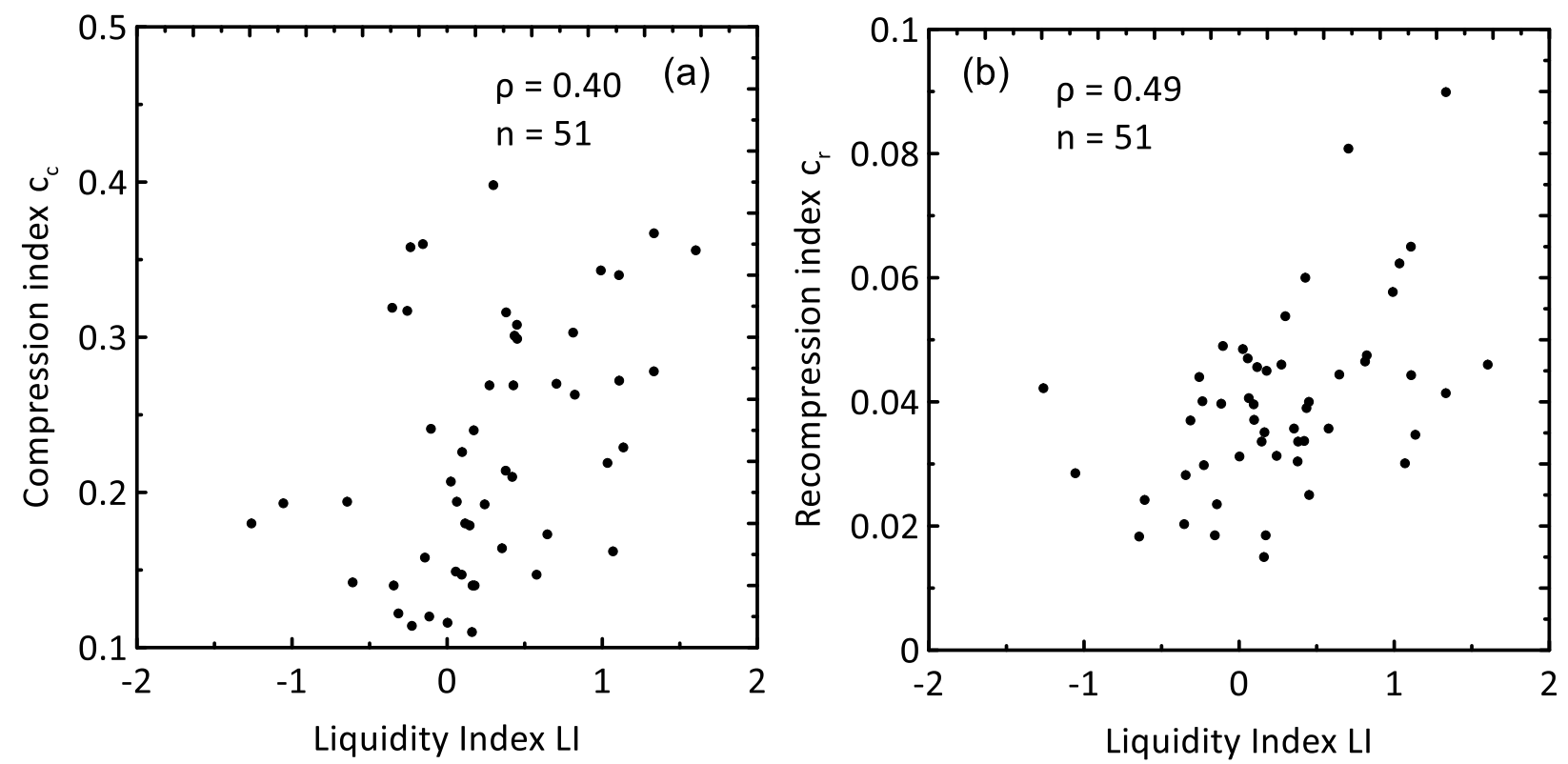

Fig. S8. Evaluation of (a) compression $c_{c}$ and $(b)$ recompression $c_{r}$ index with Liquidity Index 


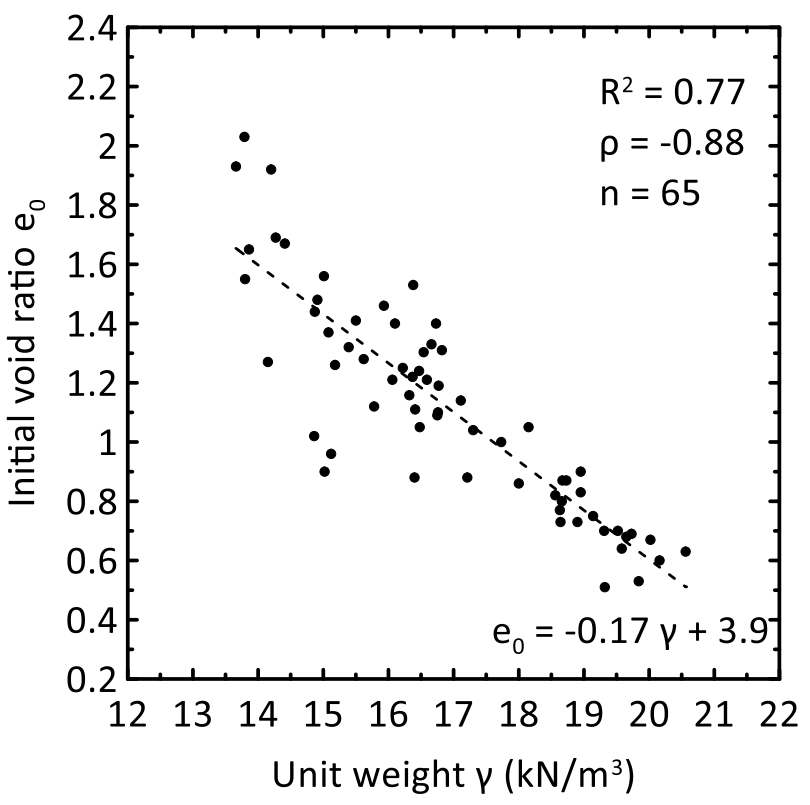

Fig. S9. Moist unit weight $(\gamma)$ with initial void ratio $\left(e_{0}\right)$ 
Table S1. Reported values and ranges of COVs for different soil properties.

\begin{tabular}{|c|c|c|}
\hline Property or test & Reported COV (\%) & Source \\
\hline Angle of friction (various soils) & 9 & Lumb (1966) \\
\hline Angle of friction (sands) & $5-15$ & Lee et al. (1983) \\
\hline Angle of friction (sands) & $2-5$ & Lacasse and Nadim (1996) \\
\hline Angle of friction (sands) & $5-15$ & Lumb (1974) \\
\hline Angle of friction (clays) & $12-56$ & Lee et al. (1983) \\
\hline Angle of friction (clays) & 40 & Kotzias et al. (1993) \\
\hline Angle of friction (alluvial soils) & 16 & Wolff (1996) \\
\hline Angle of friction (tailings - copper) & $8-12$ & Baecher et al. (1983) \\
\hline Angle of friction (tailings - uranium) & 17 & Baecher et al. (1983) \\
\hline Angle of friction (tailings - gypsum) & 14 & Baecher et al. (1983) \\
\hline Cohesion (undrained, clays) & $20-50$ & Lee et al. (1983), Lumb (1974) \\
\hline Cohesion (undrained, sands) & $25-30$ & Lee et al. (1983) \\
\hline Compressibility & $18-73$ & Lee et al. (1983) \\
\hline Compressibility (all soils) & $25-30$ & Lumb (1974) \\
\hline Compression, recompression index $\left(c_{c}, c_{r}\right)$ & $25-50$ & Lumb (1974) \\
\hline Consolidation coefficient & $25-100$ & Lee et al. (1983) \\
\hline Consolidation coefficient & $25-50$ & Lumb (1974) \\
\hline Consolidation coefficient (limited data) & $10-17$ & Tanaka et al. (2001) \\
\hline Density (apparent or true) & $1-10$ & Lee et al. (1983) \\
\hline Density (all soils) & $5-10$ & Lumb (1974) \\
\hline Density (clays, silts) & $<10$ & Baecher and Christian (2003) \\
\hline Elastic modulus & $2-42$ & Lee et al. (1983) \\
\hline Liquid limit & $2-48$ & Lee et al. (1983) \\
\hline Liquid limit (clays) & $3-20$ & Lacasse and Nadim (1996) \\
\hline Liquid limit (clays, silts) & $6-30$ & Baecher and Christian (2003) \\
\hline Moisture content (clays) & $6-63$ & Lee et al. (1983) \\
\hline Moisture content (clays, silts) & $8-30$ & Baecher and Christian (2003) \\
\hline Permeability (all soils) & $200-300$ & Lee et al. (1983), Lumb (1974) \\
\hline Plastic limit & $9-29$ & Lee et al. (1983) \\
\hline Plastic limit (clays) & $3-20$ & Lacasse and Nadim (1996) \\
\hline Plastic limit (clays, silts) & $6-30$ & Baecher and Christian (2003) \\
\hline Plasticity index & $7-79$ & Lee et al. (1983) \\
\hline Relative density & $10-40$ & Baecher and Christian (2003) \\
\hline Specific gravity & see density & Lee et al. (1983) \\
\hline Unconfined compressive strength & $6-100$ & Baecher and Christian (2003) \\
\hline Unit weight (submerged, all soils) & $0-10$ & Lacasse and Nadim (1996) \\
\hline Void ratio & $13-42$ & Lee et al. (1983) \\
\hline Void ratio (all soils) & $15-30$ & Lumb (1974) \\
\hline Void ratio, porosity (all soils) & $7-30$ & Lacasse and Nadim (1996) \\
\hline
\end{tabular}


Table S2. Compressibility and permeability parameters for different stress level for Soulou spoil heap

\begin{tabular}{|c|c|c|c|c|c|c|c|c|c|c|}
\hline & \multirow{2}{*}{\multicolumn{4}{|c|}{$\begin{array}{c}\text { Constrained Modulus } E_{s} \\
(\mathrm{MPa})\end{array}$}} & \multirow{3}{*}{$\mathrm{C}_{\mathrm{c}}$} & \multirow{3}{*}{$C_{r}$} & \multirow{2}{*}{\multicolumn{4}{|c|}{$\begin{array}{l}\text { Coefficient of Permeability k } \\
(\mathrm{cm} / \mathrm{s})\end{array}$}} \\
\hline & & & & & & & & & & \\
\hline & $\begin{array}{l}50- \\
100\end{array}$ & $\begin{array}{l}100- \\
200\end{array}$ & $\begin{array}{l}200- \\
400\end{array}$ & $\begin{array}{l}400- \\
800\end{array}$ & & & 100 & 200 & 400 & 800 \\
\hline $\mathrm{n}$ & 61 & 61 & 61 & 61 & 61 & 61 & 61 & 44 & 44 & 44 \\
\hline$\mu$ & 1.9 & 2.7 & 4.0 & 6.4 & 0.216 & 0.037 & $4.910^{-7}$ & $3.210^{-7}$ & $2.010^{-7}$ & $1.110^{-7}$ \\
\hline$\tilde{\mu}$ & 1.6 & 2.4 & 3.5 & 6.2 & 0.194 & 0.037 & $3.010^{-7}$ & $1.910^{-7}$ & $1.210^{-7}$ & $6.710^{-8}$ \\
\hline$\sigma$ & 1.1 & 1.4 & 1.8 & 2.7 & 0.081 & 0.015 & $4.910^{-7}$ & $3.210^{-7}$ & $2.210^{-7}$ & $1.110^{-7}$ \\
\hline $\operatorname{cov}(\%)$ & 58 & 51 & 45 & 42 & 38 & 41 & 99 & 100 & 109 & 104 \\
\hline $\min$ & 0.6 & 1.0 & 1.7 & 3.2 & 0.064 & 0.013 & $1.210^{-8}$ & $1.510^{-8}$ & $7.010^{-9}$ & $3.210^{-9}$ \\
\hline $\max$ & 5.7 & 8.1 & 11.3 & 18.7 & 0.398 & 0.090 & $1.910^{-6}$ & $1.310^{-6}$ & $9.510^{-7}$ & $4.910^{-7}$ \\
\hline range & 5.1 & 7.1 & 9.6 & 15.6 & 0.334 & 0.077 & - & - & - & - \\
\hline $\min / \max$ & - & - & - & - & - & - & $0.610^{-2}$ & $1.110^{-2}$ & $0.710^{-2}$ & $0.610^{-2}$ \\
\hline
\end{tabular}

\section{References}

[1] Baecher, G. B., and Christian, J. T. (2003). Reliability and Statistics in Geotechnical Engineering, John Wiley \& Sons.

[2] Baecher, G. B., Marr, W. A., Lin, J. S., and Consla, J. (1983). "Critical Parameters for Mine Tailings Embankments." Denver, CO, U. S. Bureau of Mines.

[3] Hough, B. K. (1957). Basic soils engineering, John Wiley \& Sons, Canada.

[4] Koppula, S. D. (1981). "Statistical evaluation of compression index". Geotech Test J ASTM, 4(2), 68-73.

[5] Kotzias, P. C., Stamatopoulos, A. C., and Kountouris, P. J. (1993). "Field Quality Control on Earthdam: Statistical Graphics for Gauging". Journal of Geotechnical Engineering, 119(5), 957-964.

[6] Lacasse, S., and Nadim, F. (1996). "Uncertainties in characterising soil properties." Uncertainty'96:

Uncertainty in the Geologic Environment - From Theory to Practice (Geotechnical Special Publication 58), C. D. Shackelford, P. P. Nelson, and M. J. S. Roth, eds., ASCE, Jul 31 - Aug 3 1996, Madison, WI, 49-75.

[7] Lee, I. K., White, W., and Ingles, O. G. (1983). Geotechnical Engineering, Boston, Pitman.

[8] Lumb, P. (1966). "The variability of natural soils". Canadian Geotechnical Journal, 3(2), 74-97.

[9] Lumb, P. (1974). "Application of statistics in soil mechanics." Soil Mechanics: New Horizons., I. K. Lee, ed., 44-112, 221-239.

[10] Tanaka, H., Locat, J., Shibuya, S., Soon, T. T., and Shiwakoti, D. R. (2001). "Characterization of Singapore, Bangkok, and Ariake clays". Canadian Geotechnical Journal, 38(2), 378-400.

[11] Wolff, T. F. (1996). "Probabilistic slope stability in theory and practice." Uncertainty '96: Uncertainty in the Geologic Environment - From Theory to Practice (Geotechnical Special Publication 58), C. D.

Shackelford, P. P. Nelson, and M. J. S. Roth, eds., ASCE, Jul 31 - Aug 3 1996, Madison, WI, 419-433. 